Aus der Klinik für Hals-, Nasen- und Ohrenheilkunde der Philipps-Universität Marburg

Geschäftsführender Direktor: Prof. Dr. J.A. Werner

in Zusammenarbeit mit dem Universitätsklinikum Gießen und Marburg GmbH, Standort Marburg

\title{
A Meta-analysis of the randomized controlled trials on elective neck dissection versus therapeutic neck dissection in oral cavity cancers with clinically node- negative neck
}

\author{
Inaugural-Dissertation \\ zur \\ Erlangung des Doktorgrades \\ der gesamten Humanmedizin \\ dem Fachbereich Medizin der Philipps - Universität Marburg \\ vorgelegt von \\ Ayotunde James Fasunla \\ aus Benin-city, Nigeria
}


Angenommen vom Fachbereich Humanmedizin der Philipps-Universität Marburg

Am: 09.03.2011.

Gedruckt mit Genehmigung des Fachbereiches

Dekan: Prof. Dr. M. Rothmund

Referent: Prof. Dr. A.M. Sesterhenn

Korreferent: Prof. Dr. A. Torossian 
Dedicated to my lovely wife, children and parents 


\section{Lists of abbreviations}

AAO-HNS American Academy of Otolaryngology-Head and Neck Surgery

AHNS American Head and Neck Society

AJCC American Joint Committee on Cancer

CCRT Concurrent chemoradiotherapy

DNA Deoxyribonucleic acid

EBT External beam therapy

END Elective neck dissection

CT Computerised tomography

IJV Internal jugular vein

IMRT Intensity modulated radiation therapy

IUCC International union against cancer

MRI Magnetic resonance imaging

MRND Modified radical neck dissection

OBS Observation or therapeutic neck dissection

PET Positron emission tomography

PRISMA Preferred Reporting Items for Systematic reviews and Metaanalyses

RND Radical neck dissection

RT Radiotherapy

SAN Spinal accessory nerve

SCM Sternocleidomastoid muscle

SND Selective neck dissection

US Ultrasound 
1 Introduction 7

1.1 Relevant anatomy of the oral cavity 9

1.2 Lymphatic drainage of the oral cavity 12

1.3 Statements of problem 13

1.4 Justification of the study 13

1.5 Research question 15

1.6 Hypothesis 15

2 Study objectives 16

3 Materials and method 17

3.1 Type of study 17

3.2 Study design 17

3.3 Type of participants 17

3.4 Topography, nomenclature and physiology of the lymphatic $\begin{array}{ll}\text { system of the neck } & 17\end{array}$

3.5 Staging of oral squamous cell carcinoma 23

3.6 Diagnosing the node-negative neck 24

$\begin{array}{lll}3.7 & \text { Criteria for inclusion } & 27\end{array}$

3.8 Exclusion criteria 27

3.9 Search strategy and method for identification of study 27

3.10 Validity method of assessment 27

3.11 Type of intervention 28

3.12 The development of surgical procedures for treatment of cervical lymph node metastases $\quad 28$

3.13 Classification of neck dissection 29

3.14 Data extraction 30

3.15 Outcome measures 30

3.16 Statistical analyses 30

4 Results 32

5 Discussion 40

6 Summary 56

7 Zusammenfassung $\quad 59$ 
8 References $\quad 62$

9 Curriculum Vitae $\quad 80$

10 List of my academic teachers 82

11 Acknowledgement 83

12 Sworn declaration 84 


\section{Introduction}

Oral squamous cell carcinoma is the most prevalent of all malignancies arising from the oral cavity and could result in severe morbidities and mortality if not promptly identified and treated. It accounted for $30 \%$ of all head and neck cancers [90]. The rich lymphatic drainage in this region makes these tumors to show a high incidence of metastasis to regional cervical lymph nodes [30]. Cancers arising in the oral cavity have been demonstrated to have a high metastatic rate of well over 50\% [140]. Neck node status is the single most important prognostic factor in oral cancers and other head and neck cancers [26]. The incidence of lymph node metastases of these cancers depends largely on histo-pathologic factors like tumor thickness, perineural and microvascular invasions, lymphocytic inflammatory infiltration, pattern of tumor invasion and differentiation, and molecular tumor markers [45,58,140,150]. Tumor size greater than $2 \mathrm{~cm}$ and tumor invasion depth of more than $4 \mathrm{~mm}$ are known risk factors for nodal metastasis [97,135]. The degree of histologic differentiation and tumor staging also play a significant role in nodal metastases. The incidence of nodal metastases is higher in poorly differentiated and late stage diseases [140]. However, in the American Joint Committee on Cancer (AJCC) 2010 classification system, pT1-2N0 oral cavity squamous cell carcinomas are considered to be the early stage cancer [41]. The staging system is similar to that of the International Union Against Cancer (IUCC) 2009 [141].

A subset of oral cancer patients without clinical evidence of regional metastases is known to harbor occult metastases. Unfortunately, there is still no examination method that can validly detect micro-metastasis in cervical lymph nodes during evaluation of these patients. Available imaging methods such as computed tomography (CT) scan, magnetic resonance imaging (MRI), positron emission tomography (PET) and ultrasound-guided fine needle aspiration biopsy have been shown to have significant false-negative and false-positive rates [35]. Also, there has not been accurate biomarker that can reliably identify or predict the presence of occult cervical metastases. 
Therefore, histologic examination of the neck specimen is the single most important and reliable investigation to detect neck nodal metastasis.

The great challenges in the management of these patients by surgeons and radiotherapists include the identification of the patients with true clinically nodenegative neck (NO neck) and determination of the extent of appropriate therapy that will not be regarded as over treatment. Optimal treatment for carcinomas of the oral cavity with clinical NO neck remained a controversial issue. Primary tumor control can be achieved by an appropriate surgical operation with or without radiotherapy. However, controversies exist on the management of the neck in clinically node-negative neck (NO) patients although; the available management policies include observation, elective neck dissection, or irradiation $[71,99,169]$. Even though there is no universal consensus guideline on the management of the neck in squamous cell carcinoma of oral cavity with clinical NO necks, the predominant opinion is elective neck dissection $[117,136]$. Elective neck dissection refers to dissection of cervical lymphatics and fibrofatty tissues in the absence of an obvious clinical or radiological evidence of neck node metastasis for either staging or therapeutic purposes. Those who advocate for neck treatment stated that most of those patients whose necks are observed eventually develop nodal metastasis and are usually detected at an advanced stage of the disease with poor management outcome. The benefits of neck dissection as advocated by this group include successful reduction of regional recurrence, pathological staging of neck, avoidance of unnecessary neck irradiation and indication of cases where adjunct therapy should be employed [45,58,71,97,99,140,150,169]. Nevertheless, there is still an unresolved controversy on its benefits in the eventual regional control and survival compared with the policy of observation $[46,157]$. The advocators of observation or 'watchful waiting' policy after the removal of the primary tumor have stated that elective neck dissection in clinically NO necks is just a diagnostic staging procedure rather than a therapeutic operation hence unjustifiable [66]. They recommended close watching of the neck during follow-up of these patients and performance of therapeutic neck dissection only if cervical metastases developed [116]. 
Nevertheless, the primary oral lesion in the patients which qualify for this observation policy must have fulfilled the criteria for low risk lymphatic metastases which include small size primary tumor (less than $2 \mathrm{~cm}$ ), minimal depth invasion (e.g. less than $4 \mathrm{~mm}$ in primary tumor of the tongue), and favorable histologic differentiation $[41,135]$. They proposed a reliance on the radiological evaluation of the neck to take decision on the extent of treatment [55] and emphasized on the importance of frozen section as a guide on whether or not to proceed to neck dissection [122].

\subsection{The relevant anatomy of the oral cavity}

The oral cavity is bounded anteriorly by the vermilion border of the upper and lower lips and posteriorly by the circumvallate papillae of the tongue, the junction of the hard and soft palates, and the anterior faucial arch. However, the subsites in the oral cavity include $[6,158]$ :

- Lips: The oral cavity portion of the lip includes only the vermilion surface or portion of the lip that comes in contact with the opposing lip. The lower lip primarily drains to the submental and submandibular nodes but there could be bilateral metastasis because of the anastomoses of the lymphatic vessels with the opposite side. However, the upper lip drains primarily to the preauricular, periparotid and submandibular nodes.

- Buccal mucosa: This includes the mucosa of upper and lower lips, cheek mucosa, upper and lower bucco-alveolar sulci (vestibule of mouth) and retromolar trigone. The lymphatics from buccal mucosa drain to the periparotid, submental and submandibular nodes.

- Upper and lower alveolar ridges and gingiva: Also known as upper and lower gums. The lymphatic drainage of the buccal aspect is to the submental and submandibular nodes while that of the lingual aspect is to the upper deep jugular and retropharyngeal nodes.

- Hard palate: extends from the inner surface of the superior alveolar ridge to the posterior edge of the palatine bone. The lymphatic drainage is into the jugular and retropharyngeal nodes.

- Oral tongue: is the anterior $2 / 3^{\text {rd }}$ of the tongue which is mobile and extends from the tip to the circumvallate and the junction at the floor of 
the mouth. It has four anatomical areas: tip, lateral borders, and dorsal and ventral surfaces. The anterior portion of oral tongue drains into the submental nodes while the lateral portion drains into the submandibular and upper jugular nodes. There is a rich lymphatic network with bilateral communication across the midline; therefore drainage also enters contralateral neck nodes.

- Floor of mouth: is a semilunar space extending from the lower alveolus to anterior tonsillar pillars posteriorly. It has both superficial and deep lymphatic drainage system. The superficial system crosses randomly in the midline and drains into the submandibular nodes bilaterally. The deep system drains into the ipsilateral submandibular and upper jugular nodes.

- Retromolar trigone: is a triangular shaped area overlying the ascending ramus of the mandible from the last molar (base of the triangle) to the apex which terminates in the maxillary tuberosity superiorly. The lymphatic drainage of this trigone is to the upper deep jugular nodes. 
Figure 1: Diagrammatic illustration of anatomy of the Oral cavity and its subsites (Pictures adapted from Beth Israel Medical Center, St. Luke's and Roosevelt Hospitals, New York).
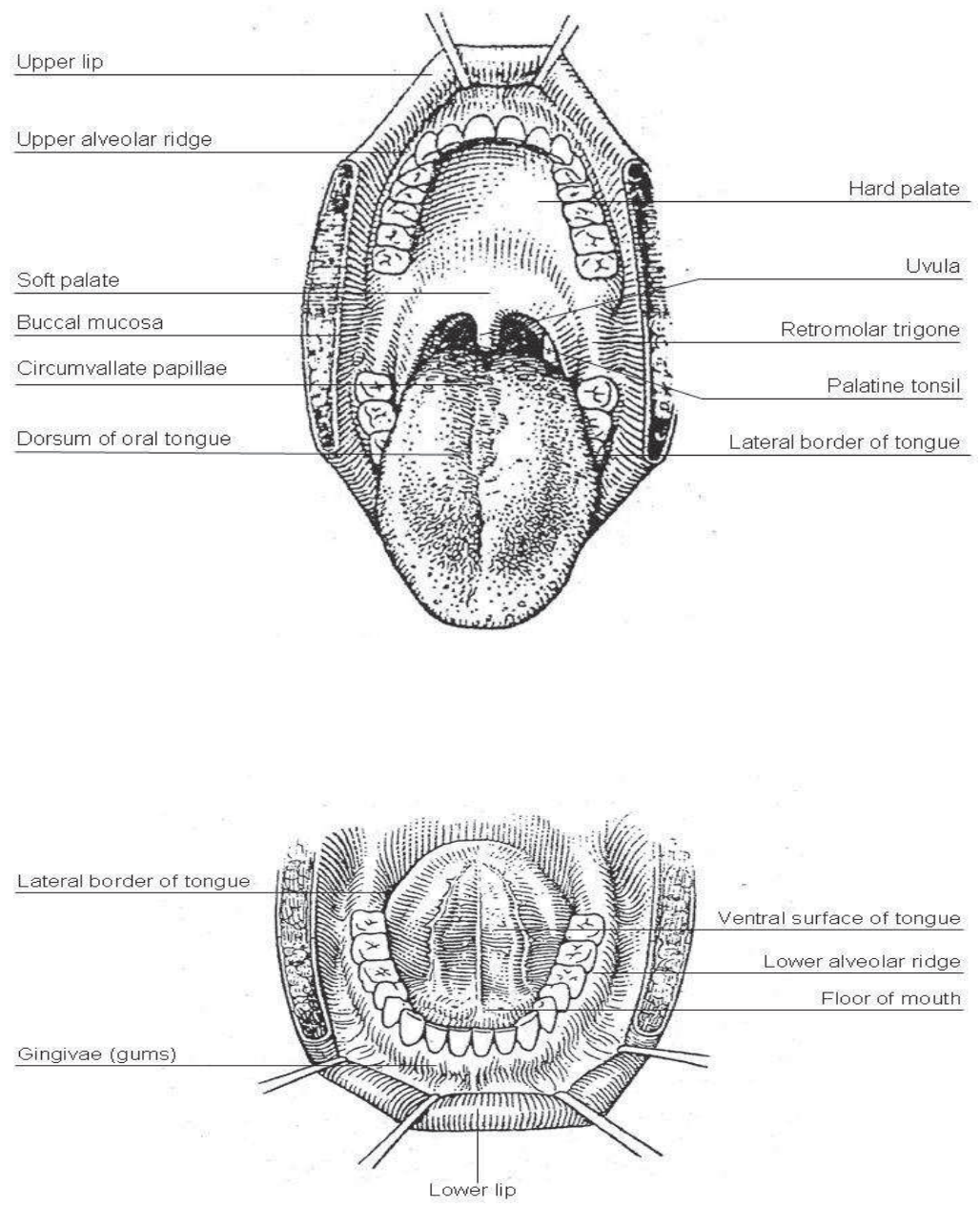


\subsection{Lymphatic drainage of the oral cavity}

The oral cavity has an extensive lymphatic drainage system. Several important lymph node groups act as first-echelon nodes for the oral cavity. In the submental triangle, two or three nodes lie on the omohyoid muscle. The submandibular triangle contains six or more nodes which lie on the surface of the submandibular gland. Included within this triangle are the facial nodes, preand postvascular, which are related to facial artery. Alveolar ridge, lip, and oral vestibule commonly drain to the submental and submandibular nodes (level I) $[6,158,162,163]$.

More inferiorly, the superior deep jugular nodes are major target of drainage from the oral cavity (Level II). They are located along the superior aspect of the internal jugular vein between the levels of the digastric and omohyoid muscles. Less common nodal groups receiving the primary lymphatic from oral cavity include the lateral retropharyngeal nodes and the nodes adjacent to the inferior portion of the parotid gland (periparotid nodes). Cancer of the hard palate with extension into the maxillary sinus and buccal cancers can drain into the retropharyngeal and periparotid nodes respectively. As multiple cervical nodes become involved with metastasis, spread to the middle jugular nodes (level III) occurs $[6,88,158,162,163]$.

The study by Rouviere has shown that the lymphatic drainage of the mucosal surfaces of the head and neck occur relatively constant and to predictable routes, not in haphazard fashion [127]. Lindberg [92] in 1972 demonstrated that the lymph node groups most frequently involved in patients with cancers of the oral cavity are the superior cervical lymph nodes. Furthermore, these cancers frequently metastasize to both sides of the neck. However, in the absence of metastasis to the first echelon lymph nodes, tumors of the oral cavity rarely involve the inferior cervical lymph node groups. Shaha et al [134] found metastasis in nodes of the posterior triangle of the neck in only $5 \%$ of patients with cancers of the oral cavity. These studies have led to the now popular practice of removing only the submental, submandibular, superior and middle jugular lymph nodes (Level I, II and III) in patients having cancer of the oral 
cavity with clinically node-negative neck (NO Neck). This procedure is known as the supraomohyoid neck dissection and has been shown to be a valid staging procedure in these patients $[16,79,162]$ and is an example of how knowledge of the lymphatic anatomy of the oral cavity has led to effective management of lymphatic metastasis.

\subsection{Statements of the problem}

1) Which patients with clinical NO neck actually have no cancer cells in the cervical lymphatics?

2) Which patients with clinical NO neck will eventually develop neck node metastasis?

3) Which treatment modality is most optimal and least morbid for the treatment of clinical NO neck in oral carcinomas?

4) Does elective neck dissection in NO neck disease confer significant outcome benefits compared to the policy of observation or watchful waiting?

\subsection{Justification of the study}

There is no greater controversy on the management of head and neck cancers than the optimal treatment for clinical NO necks. Researchers have demonstrated that clinical NO necks have shown occult metastases in about $30 \%$ or higher, depending on the size, site of primary tumor and the histological diagnostic methods $[21,118]$. The great challenge that is being faced by the head and neck oncologists and surgeons is the correct identification of the subset of head and neck cancer patients, of which oral carcinoma constitutes about 30\% [90], without micro metastases to the cervical lymph nodes. Clinical palpation of the neck combined with the radiological investigative tools has not been able to correctly identify all these patients [39,102,130]. Despite the increase in knowledge and advancement in cancer management, there is still no method to determine correctly the real micro metastatic disease free neck. Although squamous cell carcinoma of the oral cavity is a locally aggressive disease with a great tendency for loco-regional and distant metastasis, researchers have shown that not all the cancers will metastasize, especially at 
the early stage. Treating the neck which is actually node-negative means incurring unnecessary costs, prolong hospital stay and causing avoidable morbidity. However, when the neck is not included in the management plan for the primary tumor in a clinically NO neck but with actually unrecognized micro metastases, the implication of this is poor treatment outcome with increased morbidity and mortality rate.

The morbidity from the disease usually results from the impairment of the inherent physiologic functions that usually take place in the head and neck region. This may include problems with breathing, swallowing, phonation, speech, olfaction and taste. However, the advancement in management strategies of oral squamous cell carcinoma, which includes significant locoregional disease control, surgical reconstruction to restore these functions and rehabilitation, has significantly reduced these loco-regional morbidities. The quality of life of these oral cancer patients has also improved as compared to the past, even in those who eventually succumbed to distant metastasis or the disease progression. Despite the advances in cancer therapies, it is only possible to achieve an increase survival outcome or cure in patients with early disease if appropriate and optimal therapy is offered. The patients presenting with late stage diseases are usually left to faith and palliative therapies are usually offered.

The reality is that some patients with a clinical NO neck indeed have no cancer cells in their cervical lymphatics and their neck must not be over treated. In employing proper oncologic therapy for the neck, one must balance the desire to preserve the present function of the neck with the wish to prevent future morbidity or loss of neck function. This requires that all persons involved in the multimodality treatment of oral carcinomas; surgeons, radiation oncologists, and medical oncologists be open to trying a unique therapeutic approach that may achieve the desired goal, while minimizing morbidity. Although there are many available retrospective studies on oral cancer patients with clinical NO necks and modalities of therapies but there is no consensus on the unique therapeutic approach. Few prospective studies are available but there is still 
inconclusive evidence on whether elective neck dissection is of any value over observation/ therapeutic neck dissection in oral cancers with NO neck. Most of these studies have study designs which are opened to bias and their sample sizes are small. Therefore, a systematic review of prospective randomized controlled trials is needed to answer these questions owing to the inherently biased nature of available studies. Only few of such randomized controlled trials are available in the literature and none of these studies have a study population above eighty patients. Therefore a critical assessment and interpretation of the literatures which combine and compare the results of these studies with a meta-analysis is necessary for a better evidence to support either of these two modalities of treatment. This study therefore systematically reviewed the existing published literatures on the unresolved questions of the benefits of elective neck dissection in oral cancers with NO neck. Meta-analysis was then performed on published data of randomized control trials on elective versus observation/ therapeutic neck dissection.

\subsection{Research question}

Does elective neck dissection provide therapeutic benefit to patients with oral squamous cell carcinomas with clinical NO neck?

\subsection{Hypothesis}

Elective neck dissection does not provide therapeutic benefit to patients with oral squamous cell carcinomas with clinical NO neck. 


\section{Study objectives}

The scientific aim of this study is to assess the benefits of elective neck dissection in oral squamous cell carcinomas with clinically node-negative neck. All the available published randomized controlled trials on the subject matter were pooled together in a meta-analysis:

1. To evaluate the effectiveness of elective neck dissection in the successful reduction of neck node recurrence in oral squamous cell carcinoma with clinical NO neck

2. To determine and compare the disease specific death rate of elective neck dissection to policy of observation in oral squamous cell carcinoma with clinical NO neck.

3. To compare the survival outcome of elective neck dissection to the policy of observation in oral squamous cell carcinomas 


\section{Materials and method}

\subsection{Type of study}

This was a comprehensive systematic review of all relevant studies which compared elective neck dissection to the policy of observation/ therapeutic neck dissection in oral squamous cell carcinoma with clinical NO neck. The staging of oral squamous cell carcinoma was as described by the American Joint Committee on Cancer 2010 classification system [41] which was similar to that of the International Union Against Cancer (IUCC) 2009 [141]. In the metaanalysis, the PRISMA (Preferred Reporting Items for Systematic reviews and Meta-Analyses) guideline [101] for randomized trials was followed.

\subsection{Study Design}

It was a meta-analysis of all prospective randomized controlled trials on elective neck dissection versus observation/ therapeutic neck dissection for clinical NO neck in oral cancers.

\subsection{Type of participants}

All age groups with the diagnosis of oral squamous cell carcinoma with NO neck disease.

\subsection{Topography, nomenclature and physiology of the lymphatic system of the neck}

The head and neck region has a rich network of lymphatic vessels draining from the base of skull through the jugular nodes, the spinal accessory nodes and the transverse cervical nodes down to the venous jugulo-subclavian confluent or the thoracic duct on the left side and the lymphatic duct on the right side $[65,158]$. Embryologically, the lymphatic vascular system develops from buds of venous endothelium that unite to form vessels [158]. These lymphatic vessels are lined by contractile endothelial cells which contain actin-like filaments. The physiologic function of the lymphatic system is to return interstitial fluids, plasma, and cells to the blood stream. Continuous contraction of the lymph vessels, the pumping action of adjacent blood vessels, and 
compression of the interstitial tissue by the surrounding muscles allow passage of lymph in the interstitium through clefts and into the lymphatic capillaries [13].

In the classic model, lymph flows from the capillaries through afferent vessels and into the marginal sinus in the cortex of the first echelon lymph node. The marginal sinus then drains into the hilar efferent channels directly or into smaller channels that penetrate and form a complex anastomotic network in the medulla of the lymph node. From the hilar efferent channels, lymph flows into the lymphatic trunks, joining lymph from neighboring groups of nodes. The valved lymphatic trunks then drain into three terminal collecting ducts: the thoracic, subclavian, and right lymphatic ducts. Lymph is then returned to the venous system at the junctions of the internal jugular and subclavian veins. Sometimes, lymph flow may completely bypass any intercurrent lymph node via pericapsular channels that have been demonstrated to connect the afferent and efferent lymphatics [171]. Processes like metastatic tumor cell infiltration and reactive lymph node hyperplasia that increase the hydrostatic pressure in the intervening lymph node have been shown to increase the flow through the path of least resistance at the pericapsular channels $[119,146]$.

Rouviere is credited with the classic anatomic description of the lymphatic drainage of the head and neck based on anatomic landmarks found on palpation [127]. Although his description is exhaustive and produced an influential classification but it has been further modified by others to suit the need of clinicians $[53,54,94,142]$. Clinically, the roughly 300 lymph nodes, 150 per side, are now generally broken down into groups or levels. The understanding of this system of lymph node levels has helped clinicians to determine the specific area of neck metastasis especially in aerodigestive cancers and in decision making on selective neck dissection. This has been classified as follows: lymph nodes at the submental and submandibular (level I), upper jugular (level II), middle jugular (level III), lower jugular (level IV), posterior triangle which contain spinal accessory and transverse cervical nerve (level V), and anterior compartment (level VI). However, there are still some clinically important lymph node groups at the head and neck region which are 
not included in any of the classic lymph node levels. These include the facial nodes (mandibular, buccinator, infraorbital, malar, and retrozygomatic), the retropharyngeal nodes of Rouviere, the tracheoesophageal and paratracheal nodes, the periparotid and intraparotid nodes, the postauricular node, the superficial occipital node, and the upper mediastinal lymph nodes [151].

Figure 2: Topography of Neck Nodes (Adapted from Robbins 2000 [123])

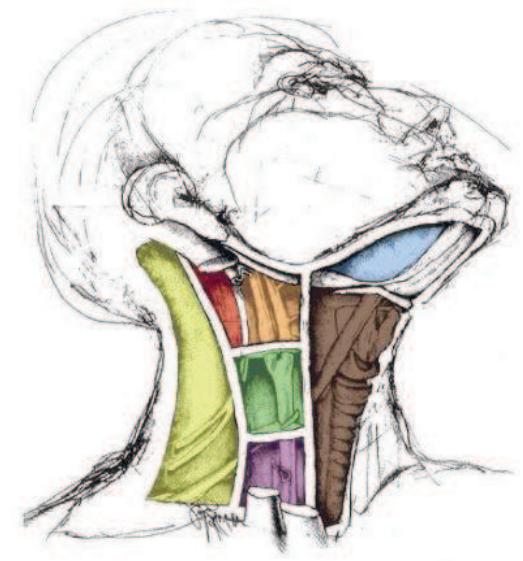

\begin{tabular}{l} 
Level I \\
Level IIA \\
\hline Level IIB \\
\hline Level III \\
Level IV \\
Level V \\
Level VI
\end{tabular}

\subsubsection{Level I Lymph Nodes}

Level I includes the lymphatic contents of the submental space (Sublevel la) and submandibular (Sublevel lb) space [142]. The submandibular space is bound anteriorly by the anterior belly of the digastric muscle, posteriorly by the posterior belly of the digastric muscle, laterally by the mandible, and superiorly by the mylohyoid and hyoglossus muscles. Rouviere [127] originally described five groups of submandibular lymph nodes (preglandular, retroglandular, prevascular, retrovascular, and intracapsular submandibular lymph nodes). To this description, DiNardo [38] added the sixth ("deep" submandibular lymph 
node) even though its presence is inconsistent. The preglandular group, usually consisting of one to two nodes, is usually located anterior to the submandibular gland and lateral to the anterior belly of the digastric muscle and embedded in fibrofatty tissue. The retroglandular node, usually singular and inconsistent, is found medial to the mandible immediately posterior to the submandibular gland. The prevascular node, usually singular, lies anterior to the anterior facial vein and superficial to the facial artery. The retrovascular nodes, usually one to two in number, are somewhat more variable in location, but are frequently found in the angle between the anterior and posterior facial veins. The intracapsular or intraglandular nodes are located within the parenchyma of the submandibular gland. The inconsistent "deep" submandibular node is located deep to the submandibular gland but superficial to the mylohyoid or hyoglossus muscles. The submental lymph nodes receive their efferent lymphatics from the skin of the chin, the mid lower lip, the tip of the tongue, and much of the mucosa of the anterior floor of mouth. The submandibular nodes receive efferent lymphatics not only from the submental lymph node but also from the medial canthal areas, lower nasal cavity, palliative vault, soft palate, maxillary and mandibular alveolar ridges, cheeks, upper and lower lips, lateral chin, and most of the anterior tongue. The superficial oral collecting lymphatic capillaries form a mucosal network with significant anastomotic crossover, which drains into a submucosal or muscular network of trunks which, in turn, drain into the submental, submandibular, and carotid triangles [17]. In addition, animal studies have demonstrated the presence of mandibular periostial lymphatics with subsequent drainage to the submandibular or upper deep cervical nodes [108].

\subsubsection{Level II Lymph Nodes}

Level II contains the upper jugular lymph nodes located around the upper one third of the internal jugular vein and adjacent spinal accessory nerve. It is bound anteriorly by the lateral border of the sternohyoid muscle, posteriorly by the posterior border of the sternocleidomastoid muscle, and superiorly by the skull base. The inferior border is defined surgically by the carotid bifurcation and clinically and radiographically by the hyoid bone. The number of nodes 
varies from one to five but the highest node lie in contact with the posterior belly of the digastrics muscle and this is referred to as the jugulodigastric node or principle node of Kuttner [127]. Level II lymph nodes have been further subclassified into sublevel Ila and Ilb $[54,163]$. The border of the stylohyoid muscle was used to separate sublevel Ib from sublevel Ila. This has been found not to be a practical marker during clinical examination and on radiological imaging. The vertical plane which is defined by the posterior edge of the submandibular gland has now been recommended [126]. Lymph nodes that lie anterior (media) to this plane are defined as occupying level I, whereas those lying posterior (or lateral) to it are defined as occupying level II. In case of nodes which transgress this plane, the determination will be based on whether more than half of the node volume is located medial or lateral to the plane $[126,163]$. Sublevel Ila contains nodes in the region anterior to the spinal accessory nerve while Sublevel Ilb contains nodes in the region posterior to the spinal accessory nerve. The level II group receives efferent lymphatics from the facial, pre- and postauricular parotid, and submandibular, submental, and retropharyngeal nodal groups. Level II also directly receives the collecting lymphatics from the nasal cavity, pharynx, larynx, external auditory canal, middle ear, tongue, hard and soft palate, faucial tonsils, and sublingual and submandibular glands [127].

\subsubsection{Level III Lymph Nodes}

Level III contains the middle jugular lymph nodes located around the middle one third of the internal jugular vein. It is bound anteriorly by the lateral border of the sternohyoid muscle, posteriorly by the posterior border of the sternocleidomastoid muscle, and superiorly by the inferior border of level II (carotid bifurcation or hyoid bone). The inferior border is defined surgically by the junction of the omohyoid muscle and the internal jugular vein, and clinically by cricothyroid notch and radiologically by the cricoid cartilage. Level III contains a highly variable number of nodes, with a dominant supraomohyoid node, and receives efferent lymphatics from level II and level V, some efferent lymphatics from the retropharyngeal, pretracheal, and recurrent laryngeal 
nodes and collecting lymphatics from the tongue base, tonsil, larynx, hypopharynx, and thyroid gland [127].

\subsubsection{Level IV lymph nodes}

This contains the lower jugular lymph node located around the lower one third of the internal jugular vein. It is bound anteriorly by the posterior border of the sternohyoid muscle, posteriorly by the posterior border of the sternocleidomastoid muscle, superiorly by the inferior border of level III (cricothyroid notch or junction of omohyoid and Internal jugular vein or cricoid cartilage), and inferiorly by the clavicle. Level IV also contains a variable number of nodes and receives efferent lymphatics primarily from level III and level $\mathrm{V}$, some efferent lymphatics from the retropharyngeal, pretracheal, and recurrent laryngeal nodes and collecting lymphatics from the hypopharynx, larynx, and thyroid gland [127].

\subsubsection{Level V Lymph Nodes}

Level $\mathrm{V}$ contains all the lymph nodes in the posterior triangle of the neck. It is bound anteriorly by the posterior border of the sternocleidomastoid muscle, posteriorly by the anterior border of the trapezius muscle, superiorly by the mastoid process and inferiorly by the clavicle. Level $\mathrm{V}$ contains five to 10 nodes and receives efferent lymphatics from the occipital and postauricular nodes as well as collectively lymphatics from the occipital and parietal scalp, the skin of the lateral and posterior neck and shoulder, tonsils, tongue base, and nasopharynx $[127,164]$.

\subsubsection{Level VI Lymph Nodes}

Level VI, also called the anterior central compartment lymph node group, contains the lymph nodes in the visceral space. It is bound laterally by the medial borders of the carotid sheaths, superiorly by the hyoid bone, and inferiorly by the suprasternal notch. Level VI receives efferent lymphatics from the thyroid gland, larynx, hypopharynx, and cervical esophagus $[127,163]$. This level has been described and separated from level III and IV by the lateral border of sternocleidomastoid muscle. Because this landmark cannot be easily 
identified on radiological imaging, medial aspect of common carotid artery has been recommended [126].

\subsection{Staging of oral squamous cell carcinoma $[41,112,141]$}

\section{Tumor}

- $\quad \mathrm{T} 1-2 \mathrm{~cm}$ or less

- $\mathrm{T} 2->2 \mathrm{~cm}$ but $\leq 4 \mathrm{~cm}$

- $\quad \mathrm{T} 3->4 \mathrm{~cm}$

- T4 (Lip) - Invades through cortical bone, inferior alveolar nerve, floor of mouth, or skin of face (i.e. chin or nose)

- T4a (Oral cavity) - Invades through cortical bone, deep (extrinsic) muscle of tongue, maxillary sinus, or skin of face

- $\quad$ T4b - Involves masticator space, pterygoid plates, or skull base, or encases internal carotid artery

\section{Node}

- NX - Cannot be assessed

- $\quad$ NO - No regional lymph nodes metastasis

- $\quad \mathrm{N} 1$ - Single ipsilateral lymph node, $<3 \mathrm{~cm}$ in greatest dimension

- $\quad \mathrm{N} 2$ - Lymph node between 3 and $6 \mathrm{~cm}$ in its greatest diameter

- N2a - Single ipsilateral lymph node, 3-6 cm in greatest dimension

- N2b - Multiple ipsilateral lymph nodes, not more than $6 \mathrm{~cm}$ in greatest dimension

- N2C - Bilateral or contralateral lymph nodes, not more than $6 \mathrm{~cm}$ in greatest dimension

- $\quad$ N3 - Lymph node(s) $>6 \mathrm{~cm}$ in greatest dimension

\section{Metastasis}

- $\quad \mathrm{M} 0$ - none

- $\quad \mathrm{M} 1-$ yes 


\section{Stage grouping}

- I - T1 N0

- II - T2 NO

- $\quad$ III - T3 N0, T1-3 N1

- IVA - T4a, N2

- $\quad$ IVB - T4b, N3

- $\quad$ IVC - M1

Note : T: Tumor; N: Node; M: Metastasis

\subsection{Diagnosing the node-negative neck}

Node-negative neck disease conventionally refers to clinically non-palpable neck nodes but this is a grossly inadequate and inaccurate method of identifying metastatic neck node [4,21,114,121,133]. Researchers have demonstrated that clinical NO necks have shown occult metastases in about $30 \%$ or higher, depending on the size, site of primary tumor and the histological diagnostic methods [21,118]. Some large nodes may be inflammatory while some impalpable nodes may be carcinomatous $[32,108]$. Clinical palpation of the neck is not adequate for the correct identification of patients with neck node metastasis $[39,102,130]$. Factors such as neck fat thickness, neck stiffness or contraction, pain and swelling may affect the identification of neck node by palpation. However, the combination of neck palpation and radiologic evaluation of the neck with computerized tomographic (CT) scan and/or magnetic resonance imaging, and ultrasound and ultrasound-guided fine needle biopsy for cytology of the suspected node have been shown to provide an improved accuracy of detecting metastatic neck node or diseases $[27,145,156]$. Ultrasound guided fine needle aspiration cytology is reliable to some extent at identifying lymph node metastases in carcinoma of the oral cavity and other head and neck cancers which were previously impossible. In recent publications related to the detection of cervical metastases, sensitivity rates of ultrasonography, magnetic resonance imaging (MRI), computed tomography (CT), the 18F-fluorodeoxyglucose (FDG)-positron emission 
tomography (PET) and PET/CT are in the range of about $70-80 \%$ $[3,61,83,167,168]$.

These radiological investigative tools are valuable in assessing those nodes in the head and neck sites that are not easily and readily accessible to palpation, such as the retropharyngeal, paratracheal, and upper mediastinal nodes, and in assessing extranodal disease. The malignancy criteria on CT scan and MRI include minimal diameter of $15 \mathrm{~mm}$ for nodes located in level II and $10 \mathrm{~mm}$ for nodes located in other levels; spherical shape, groups of three or more borderline nodes (1 to $2 \mathrm{~mm}$ smaller); nodes of any size with evidence of central necrosis; and soft tissue invasion or loss of tissue planes (fat planes) $[27,39,68,102,154]$. However, these radiological investigative tools are not without limitations. Small areas of necrosis are not always depicted clearly and adipose metaplasia or area of hypovascularity could mimic necrosis on CT scan [39]. An estimated $50 \%$ of cervical metastases are less than $5.0 \mathrm{~mm}$ [39]. Studies have also shown that 46 - 67\% cases of malignant lymph node matastases will be missed by CT scan, confirmed by histologic evaluation of whole neck specimens $[39,56]$. In a study, the sensitivity of CT staging is estimated to be $25 \%$, and the specificity $77 \%$ [130]. Therefore, pathologic staging is the most accurate tool available to assess the status of the cervical lymphatics.

Extracapsular extension of nodal metastasis, on the other hand, can be most reliably detected only on pathologic examination of the node in question because current radiologic imaging techniques are not adequately accurate. However, as individual predictors of metastasis, the histologic data have not been consistently and strongly correlated. Histopathologic factors like tumor thickness, perineural and microvascular invasions, lymphocytic inflammatory infiltration, pattern of tumor invasion and differentiation, and molecular tumor markers have been advocated to be reliable metastastic potential parameters $[45,58,97,150,166]$. A report on a multivariable clinicopathologic scoring system in which points were allotted to each individual variable or predictor has been document [135]. The points were then summed up to yield a multivariable 
metastatic potential, based on characteristics of the primary tumor. Though limited to the oral cavity and oropharynx, this innovation in histologic examination may prove valuable in assessing the risk of cervical metastasis.

Another innovation, which has emerged from the advances in molecular genetics, is molecular staging of head and neck cancer patients [155]. Molecular staging uses the polymerase chain reaction to amplify and assay the tumor suppressor gene p53 (from the surgical specimen). The molecular probing is highly sensitive and is reported to have the capacity to detect one cancer cell among 10,000 normal cells. Although only available at a few centers, preliminary data showed that these techniques improve the ability to predict loco-regional recurrence [18].

Histologic features of the primary tumor have been combined with molecular genetics to predict cervical lymph node metastasis. This study combined histologic features of the primary tumor with immunohistochemical studies of cell adhesion molecules, tumor suppressor genes and DNA analysis of oncogenic amplification. Their correlation has been used to predict the possibility of cervical metastasis in patients with laryngeal carcinoma [150]. This type of study may actually revolutionize the way oral cancers and other head and neck cancers are staged in the future.

In the treatment of oral squamous cell carcinomas, control of the primary tumor is very important to the survival outcome of the affected patient. Hence, the single most important therapeutic intervention for oral squamous cell carcinoma is the complete surgical removal of the primary tumor. This may sometimes not be achievable, especially in late stage diseases due to the extent of the tumor and its relation to the vital adjacent structures. Failure to achieve a complete surgical primary tumor removal will lead to poor treatment outcome and even, early death [82]. Cervical lymph node metastasis increases the risk of locoregional recurrence and distant metastatic spread and correlates with a 50\% decrease in survival $[42,52,87]$. 
3.7 The Criteria for inclusion in the study include:

- The studies must be randomized controlled trials

- The patients in the studies must have no clinical and radiological evidences of neck node metastasis (NO neck)

- The study must have compared elective neck dissection (END) with observation / therapeutic neck dissection (OBS) in patients with oral cavity cancers

3.8 Exclusion criteria included studies which did not meet the above mentioned criteria or in which the randomization was missing.

\subsection{Search strategy and method for identification of study}

A comprehensive search of articles published in English in the following electronic databases: MEDLINE (1966 - 2010), EMBASE (1988 - 2010), Cochrane Central Register of Controlled Trials, Scopus and Google scholar was carried out. Despite this restriction to articles published in English language, there was no identification of studies published in other languages. To retrieve publications reporting on randomized controlled trials on elective neck dissection versus observation/ therapeutic neck dissection in oral cavity cancers, a combined search strategy that included the following terms as both medical subject heading (MeSH) terms and text words was performed. The key terms used to search the electronic database included "randomized controlled trial", "oral cavity cancers", "elective neck dissection", "therapeutic neck dissection", "observation" and "NO neck". All, and then some of these terms were used in combination for the search. Some books and reference list of each article obtained were checked for further potential studies (Figure 3). The authors of one of the original articles [169] included in the study were contacted for additional information.

\subsection{Validity method of assessment}

The identified studies were assessed based on the intended objectives for the study. Only the trials which met the criteria were included in the meta-analysis. Data from the studies were then extracted and collated. 


\subsection{Type of intervention}

All the studies randomized the patients into two groups \{[Elective neck dissection (END) and Observation or Therapeutic neck dissection (OBS) group\}.

END group had primary neck dissection at the time of the treatment of the primary tumor.

OBS group had treatment of the primary tumor only but the neck was put under closed observation during follow up. Neck dissection was performed only when neck node metastasis was detected and this was therapeutic neck dissection.

\subsection{The development of surgical procedures for the treatment of cervical lymph node metastases}

In the $19^{\text {th }}$ century, lymphatic metastasis in patients with head and neck cancer was considered by many surgeons as a sign of an incurable disease [49]. The removal of individual lymph node metastases with the resection of the primary tumor presented a less effective therapeutic outcome in the patients at that time. In 1880, Kocher reported on the detailed description of the surgical technique for the removal of lymph nodes from submandibular triangle during the surgical treatment of tongue cancer [80]. In 1882, Volkmann reported on lymph node dissection along with resection of the internal jugular vein [160]. A short period later, the concept of prophylactic or elective removal of neck lymph nodes was developed. In 1885, Butlin recommended in his publication that during surgical excision of carcinoma of the tongue, elective removal of the neck lymph nodes must be performed [20]. In 1888, a polish surgeon called Franciszek Jawdynski described an en-bloc resection of lymph node metastases, which was later in 1906 popularised and described by Crile as radical neck dissection [32]. The morbidity and complications associated with radical neck dissection (RND) is high [49]. In order to reduce this morbidity associated with RND, a modification of the classic RND was developed at the beginning of $20^{\text {th }}$ century by surgeons so as to maintain function and at the same time not compromising oncologic treatment outcome [9,96]. Nahum described a syndrome of decreased range of abduction in the shoulder joint 
and pain following RND which has been termed 'shoulder syndrome' [104]. The cause of this syndrome is damage to or removal of the spinal accessory nerve (SAN) during neck dissection. The preservation of this structure during neck dissection was found to ameliorate this syndrome [137]. The realization that it was possible to perform a complete en-block lymphadenectomy with preservation of structures such as the spinal accessory nerve led to the development of the less morbid procedures and the original concept of which is credited to Bocca [12]. The classical modified radical neck dissection (MRND) involved the removal of cervical lymph nodes from levels I to $\mathrm{V}$ and retaining some or all the non-lymphatic structures. The ability to harvest neck nodes in an operation that limits morbidity has led to a more proactive approach to the treatment of cervical disease. In the 80's of last century, the concept of selective neck dissection (SND) was developed. This concept erupted out of the understanding that carcinomas from certain region or site of the head and neck metastasize only to specified neck levels [92]. Many clinicians now advocate selective neck dissections in those patients whose primary site characteristics would suggest a high rate of occult metastasis.

\subsection{Classification of neck dissection}

Neck dissection is a surgical procedure for the control of neck lymph node metastasis from the primary tumor. The aim is to remove all lymph nodes from one or both sides of the neck into which cancer cells might have migrated or suspected to have migrated. Various modifications of neck dissection have been described till date. However, American Head and Neck Society (AHNS) and the American Academy of Otolaryngology-Head and Neck Surgery (AAOHNS) have proposed a classification into radical neck dissection, modified radical neck dissection, selective neck dissection and extended neck dissection [124]. Radical neck dissection (RND) involves the removal of all ipsilateral cervical lymph node groups from levels I through to $\mathrm{V}$, together with SAN, sternocleidomastoid muscle (SCM) and internal jugular vein (IJV). Modified radical neck dissection (MRND) involves the removal of all lymph node groups routinely removed in a RND, but with preservation of one or more nonlymphatic structures (SAN, SCM and IJV). Selective neck dissection is 
cervical lymphadenectomy with preservation of one or more lymph node groups that are routinely removed in a RND. Its description involves the use of parentheses to denote or represent the specific levels or sublevels of neck contents removed. No non-lymphatic structures that are routinely removed by RND are removed. An increasing body of evidence suggests that "less can sometimes mean more" [50]. Prospective randomized studies which compared the efficacy of SND with that of MRND in patients with clinically node-negative neck have demonstrated the therapeutic equivalence of the two different surgical options [15,16]. Thus for oral cavity cancers, SND (I-III) is commonly performed. Extended neck dissection refers to the removal of one or more additional lymph node groups or non-lymphatic structures, or both, not encompassed by the RND [113].

\subsection{Data extraction}

The extracted data included study design and characteristics (Table 1), sample size and study group distribution (Table 2), pathologic distribution of the groups and follow up periods (Table 3), neck recurrences and metastasis (Table 4), disease-specific deaths in each group, survival and death outcome (Table 5).

\subsection{Outcome measures}

The primary endpoint variable for this meta-analysis was disease-specific death in the groups. Outcome data on overall deaths, survival, neck nodal recurrences and metastasis in each group were also obtained.

\subsection{Statistical analyses}

The analysis was performed using the $R$ program for statistical computing ( $R$ 2.10.1; "meta" package). The relative risk (RR) of disease-specific death and 95\% confidence interval $(\mathrm{Cl})$ were calculated for each individual study. Between-study heterogeneity was not found to be significant as indicated by an $1^{2}$ of $8.5 \%(p=0.350)$, however, due to the small number of studies included, both fixed-effects (Mantel-Haenszel method) and random-effects models (DerSimonian and Laird [36] method) were applied to obtain a combined RR estimate, $95 \% \mathrm{Cl}$ and $p$-value. The inverse variance method of weighting 
studies (results not shown) was also used, but the results of our meta-analysis did not differ between these methods with regard to combined RR estimates and their significance. 


\section{$4 \quad$ Results}

In the systematic review, four randomized controlled trials with a total of 283 patients were identified and these were eligible for inclusion into the metaanalyses (Table 1, Figure 3) $[46,79,157,169]$. Three of these were single-center studies which took place in France [157], India [46], and Brazil [79] respectively. The most recently completed study from Yuen et al was performed as a multi-center trial in Hong Kong [169]. These trials took place over four decades with the first patients recruited in 1966 [157] and the last in 2004 [169]. The descriptive statistics of the studies are as shown in Table 2. All the studies randomized their patients into END group and OBS group and the main study objective of each study was to determine the benefit of elective neck dissection for clinical NO neck in oral cancers. There was no statistical difference between these two groups in terms of sex and age of patients, histologic type and tumor staging. All the trials reported on pathologic distributions (Table 3), neck recurrences and metastasis (Table 4), survival and death outcome (Table 5). There were few missed data but the studies have a very low rate of interventional crossovers. However, the follow up duration varied between the studies but the least follow up period was 12 months due to death (Table 3 ). The treatment modality of the primary tumor in three studies was surgery while the study by Vandenbrouck et al had treatment of the primary tumor with interstitial curietherapy with iridium-192 [157]. All the trials had neck dissection in addition to the treatment of the primary tumor in END group. For the primary outcome of survival benefits, all the trials with the exception of the study by Kligerman et al reported no survival benefit of elective neck dissection over observation. However, all of these trials individually showed lower disease-specific death rates in the END group compared with the OBS group, but only in the study by Kligerman et al [79] was significance reached (Figure 4). However, the meta-analyses of these studies showed that elective neck dissection may reduce the risk of death from the disease thereby, increasing the chance of survival (Figure 5), \{fixed-effects model $R R=0.57,95 \%$ $\mathrm{Cl}$ of $0.36-0.89, \mathrm{p}=0.014$; random-effects model $\mathrm{RR}=0.59,95 \% \mathrm{Cl}$ of 0.37 $0.96, p=0.034\}$. 
Figure 3: Flowchart showing the process of study selection for the metaanalysis

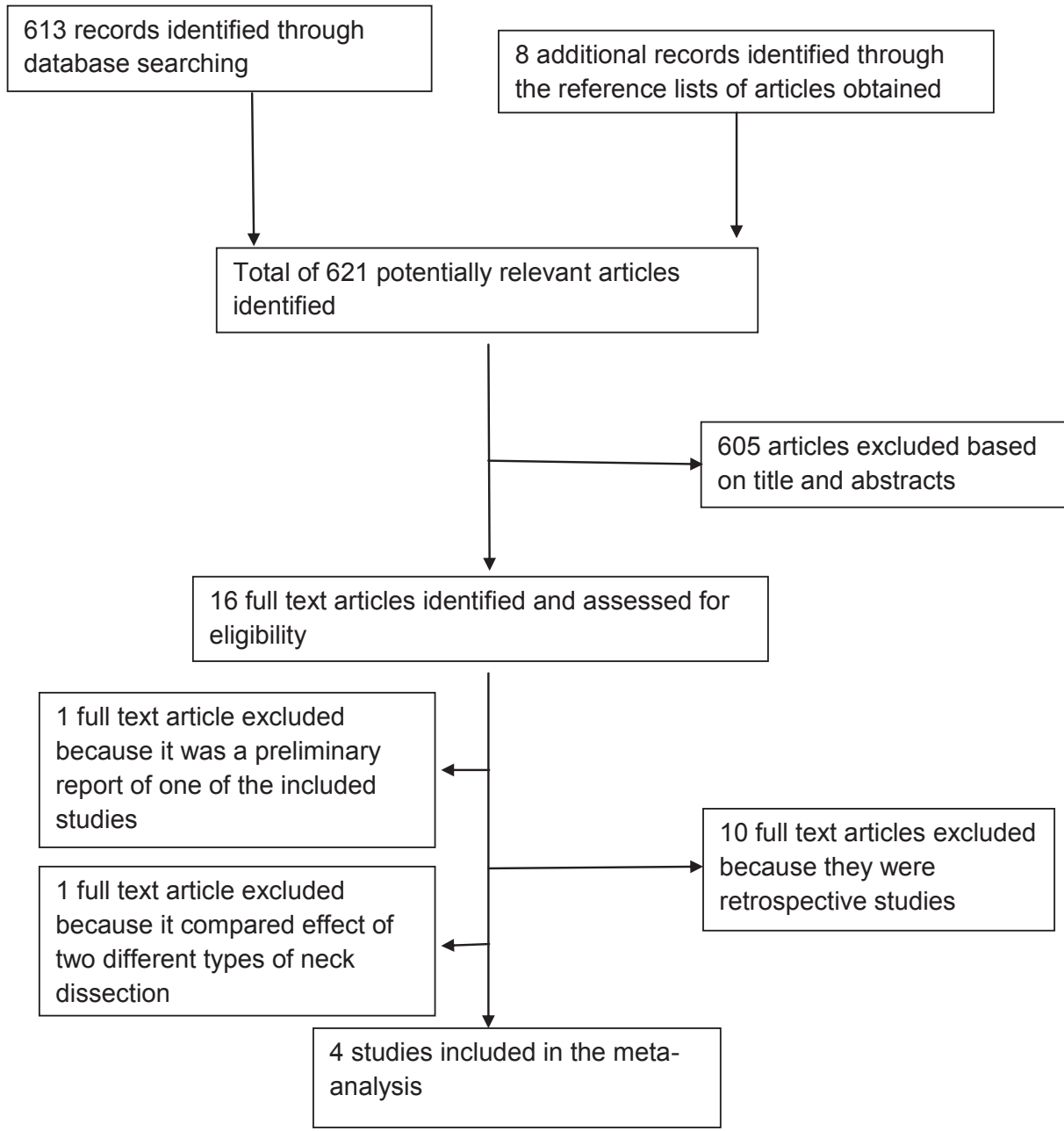




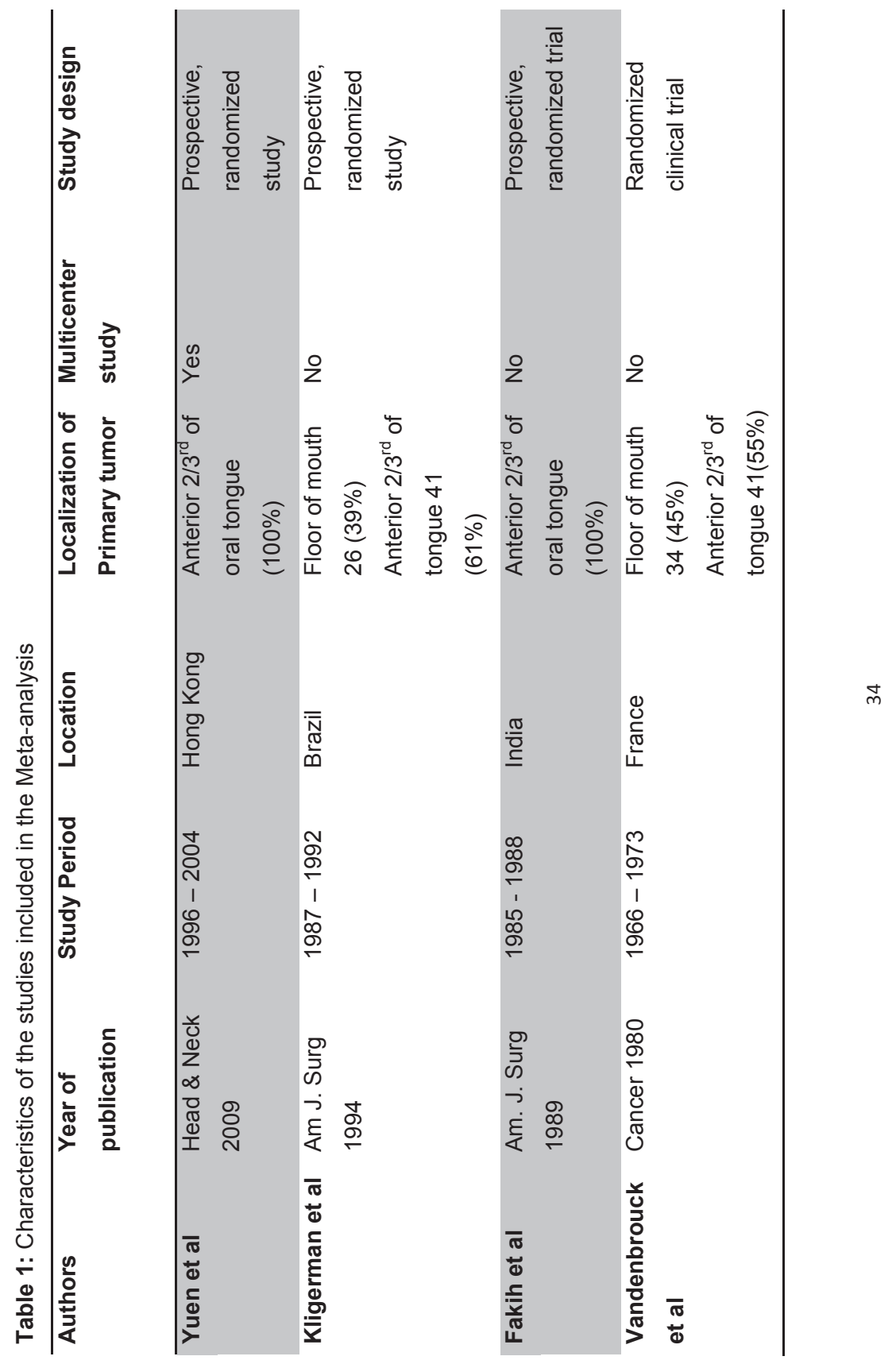




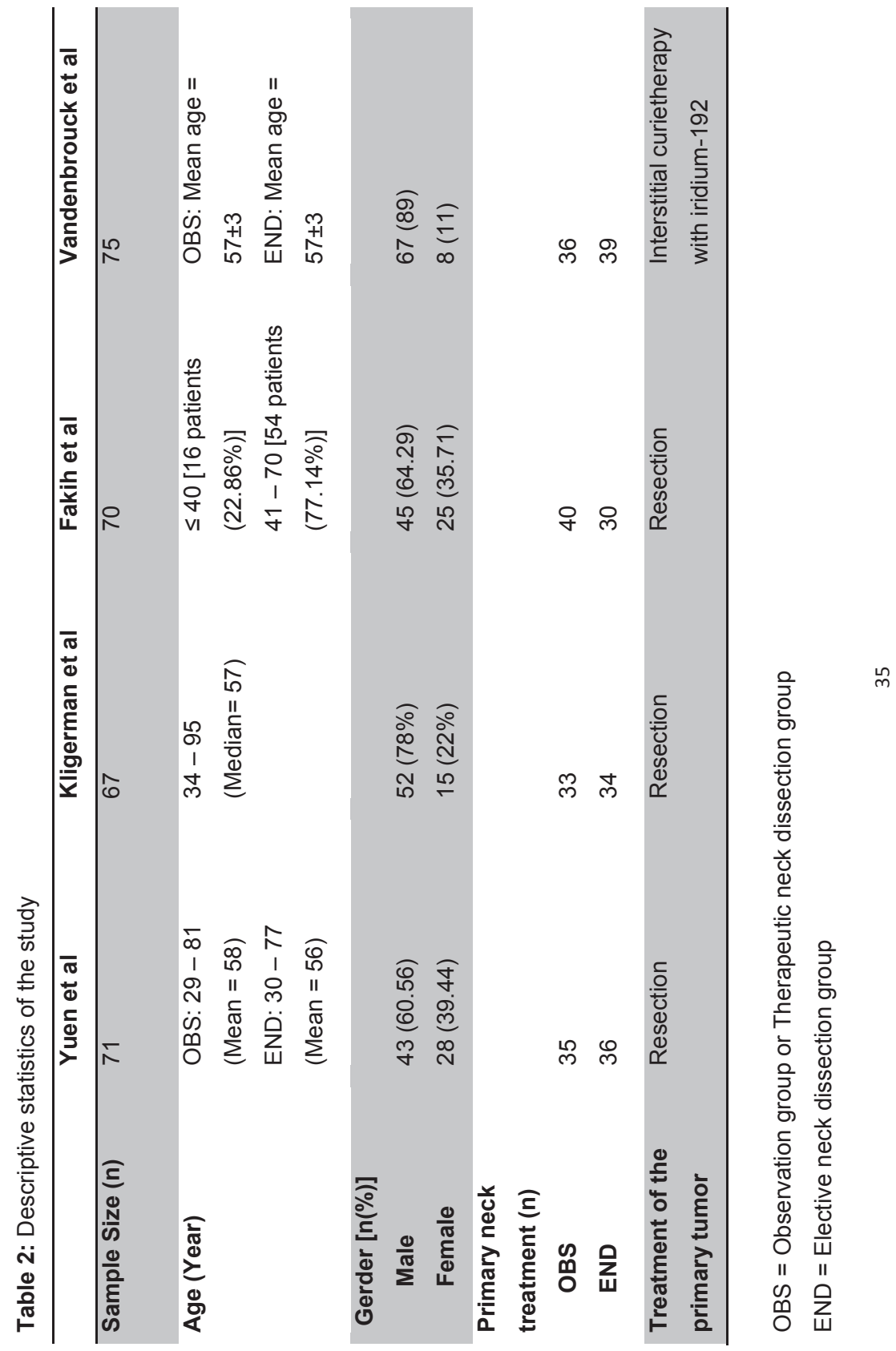




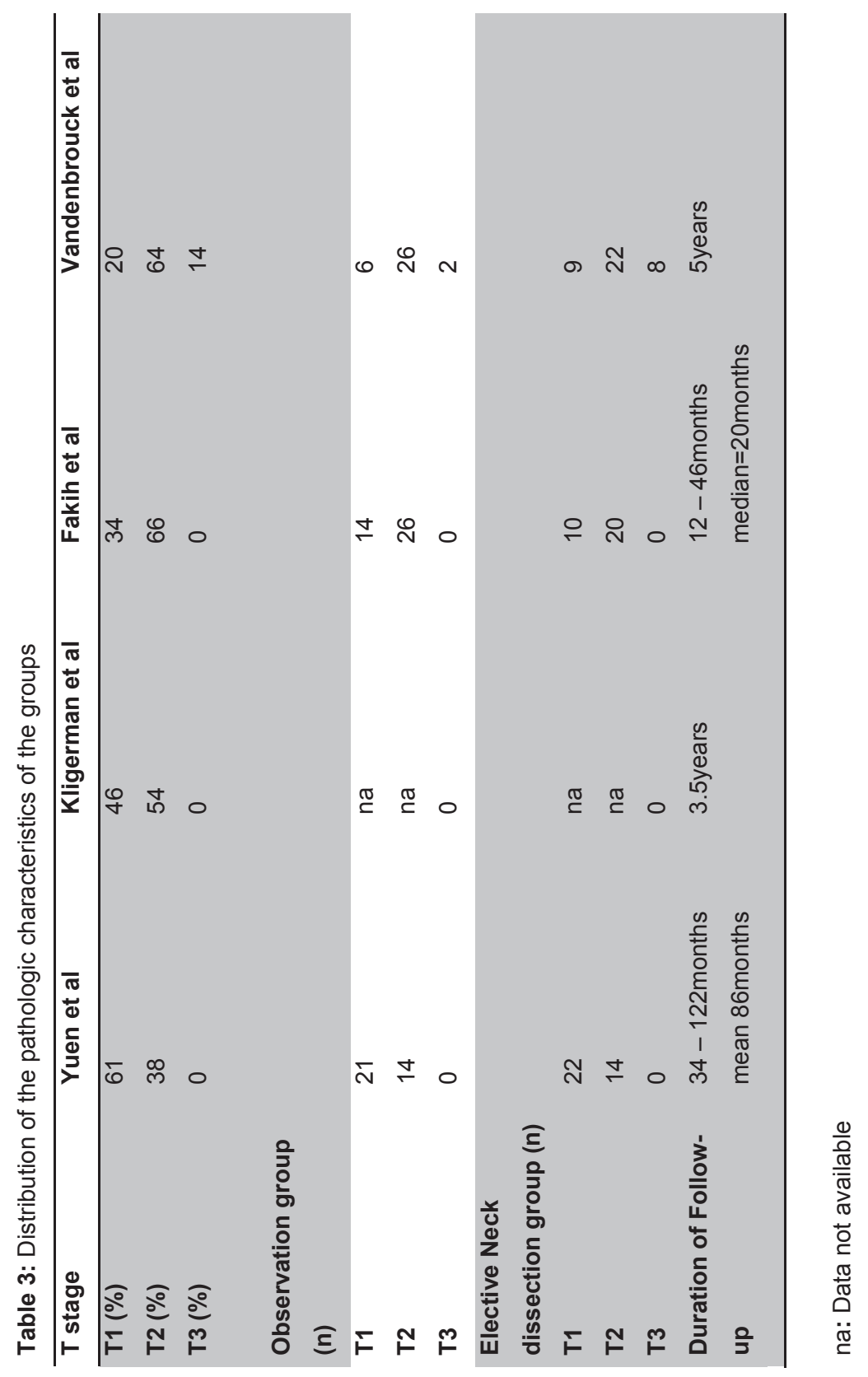




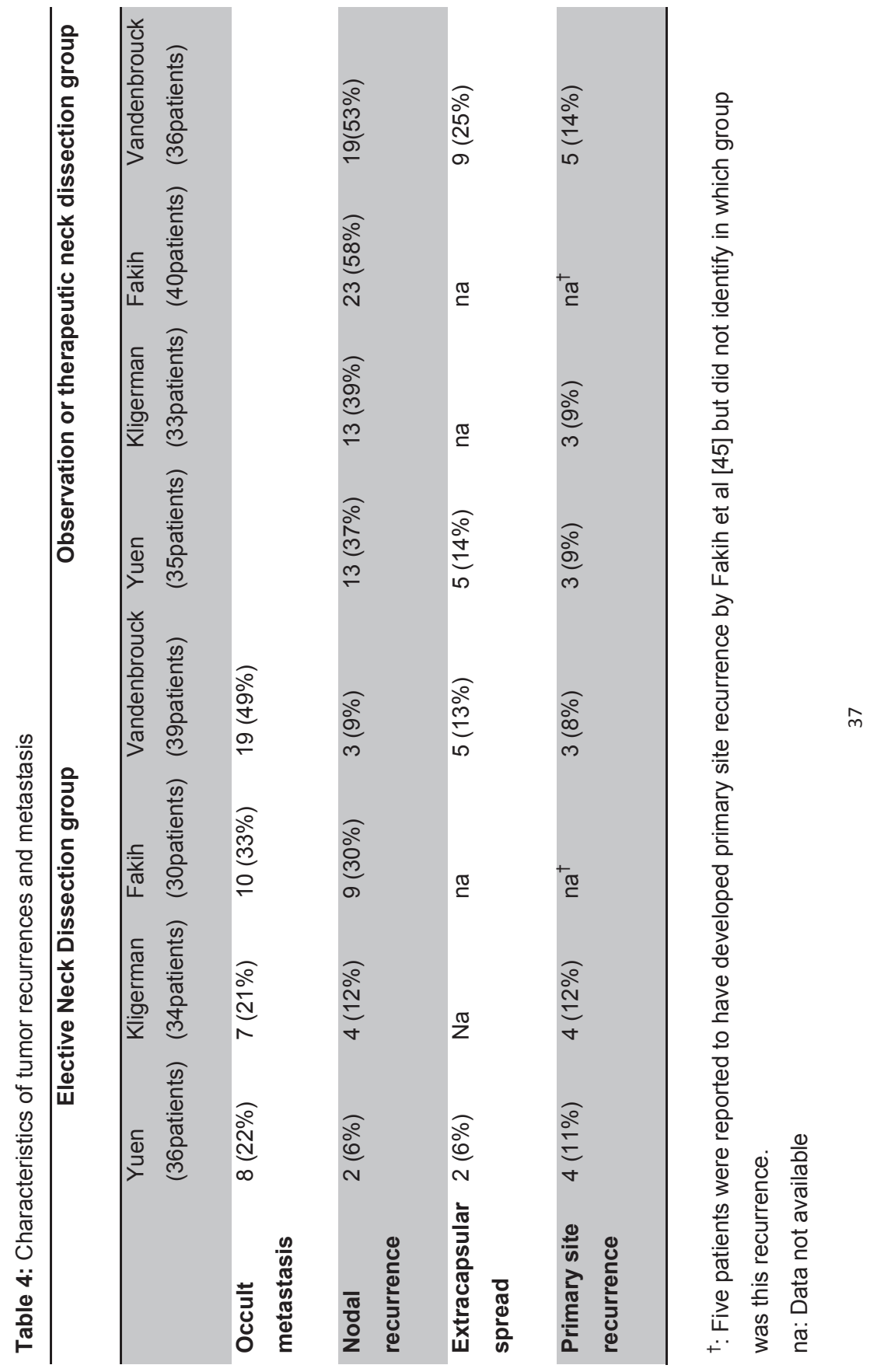




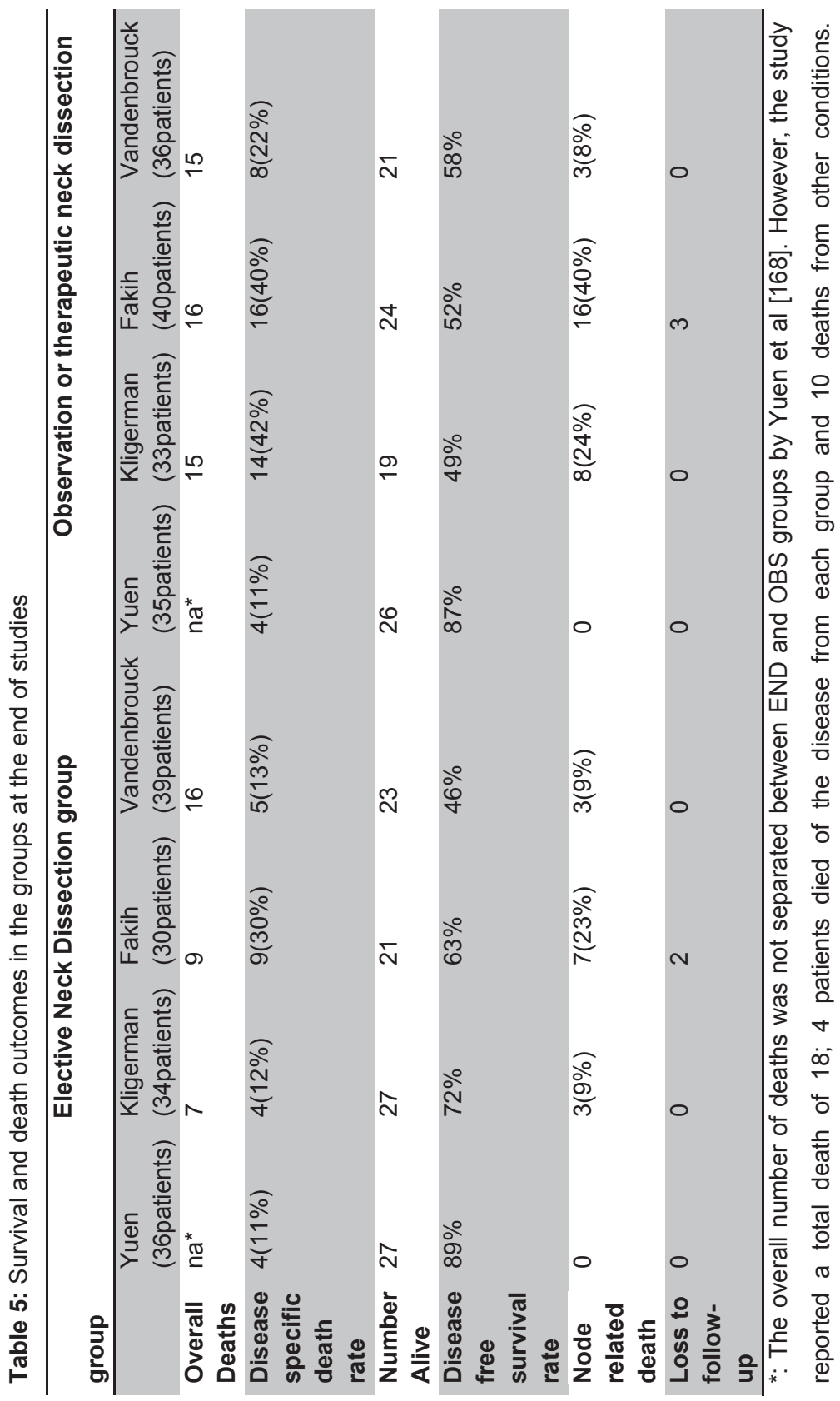


Figure 4: Forest plot showing relative risk (RR) of the disease-specific death and $95 \%$ confidence interval $(\mathrm{Cl})$ in each of the randomized controlled trials

\begin{tabular}{|c|c|c|c|c|c|c|c|}
\hline Study & END & Observation & & & & RR & $95 \%-\mathrm{Cl}$ \\
\hline Vandenbrouck et al $(1980$ & ) $5 / 39(13 \%)$ & $8 / 36(22 \%)$ & & 1 & - & 0.58 & {$[0.21 ; 1.60]$} \\
\hline Fakih et al (1989) & $9 / 30(30 \%)$ & $16 / 40(40 \%)$ & & $\longrightarrow$ & $\forall$ & 0.75 & {$[0.39 ; 1.46]$} \\
\hline Kligerman et al (1994) & $4 / 34(12 \%)$ & $14 / 33(42 \%)$ & & + & & 0.28 & {$[0.10 ; 0.76]$} \\
\hline Yuen et al (2009) & $4 / 36(11 \%)$ & $4 / 35(11 \%)$ & & & & 0.97 & {$[0.26 ; 3.59]$} \\
\hline & & & 1 & T & $T$ & $\neg$ & \\
\hline & & & 0.2 & 0.5 & 1 & 5 & \\
\hline & & & & favours & favours & & \\
\hline & & & & END & Observation & & \\
\hline
\end{tabular}

Figure 5: Forest plot showing relative risk (RR) of disease-specific mortality and $95 \%$ confidence interval $(\mathrm{Cl})$ in each of the studies and the combined estimates

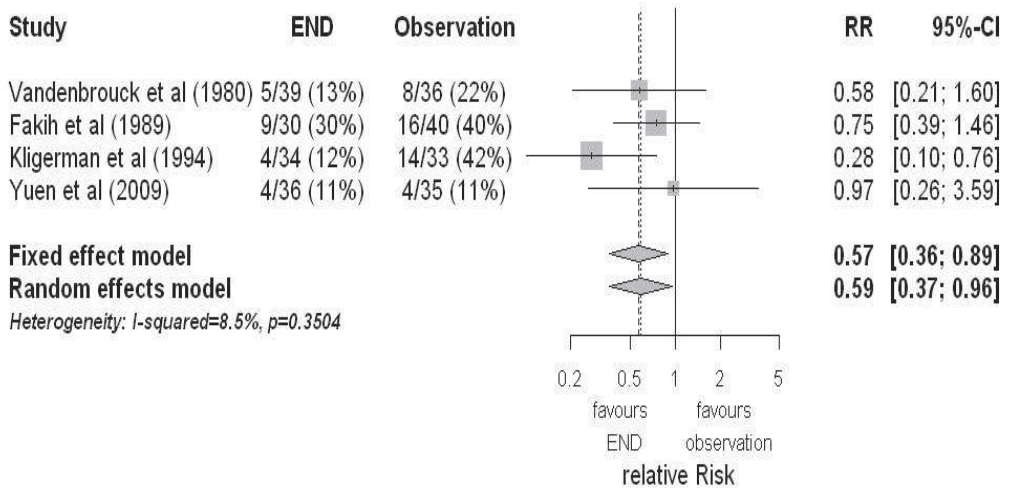

OBS = Observation/ Therapeutic neck dissection group

END = Elective neck dissection group 


\section{Discussion}

An in-depth review of all the randomized controlled trials included in this metaanalysis showed that there were a few variations in the trials such as race, period of study, and duration of follow-up. Although the data used in this metaanalysis were from different parts of the world, the heterogeneity of the trials were tested and there was no statistical significant difference $\left[I^{2}=8.5 \%\right.$, $\mathrm{p}=0.3504$ ] (Figure 5). In all the randomized controlled trials included in this meta-analysis, there were more male patients with oral cavity cancers than female. This may be because more males were exposed to the predisposing factors especially cigarette/tobacco and alcohol than the females. However, a close inspection of all the studies showed that, in the most recent study by Yuen et al [167], there was a significant reduction in the gender ratio difference. This may be because of the change in the social life-style of women in most part of the developed and developing countries which is now similar to that of men [138].

The majority of oral cavity cancers are of squamous cell origin and the site most commonly affected by this tumor in the oral cavity is the anterior two thirds of the tongue and followed by the floor of the mouth [6]. Other subsites of the oral cavity are infrequently involved [6]. This may explain the reason why all the studies in this meta-analysis reported on the cancer of the anterior two third of the tongue (Table 1). However, Kligerman et al and Vandenbrouck et al reported on additional few cases of cancers of the floor of the mouth in their series $[79,157]$.

Over 6,000 new cases of oral cavity carcinomas are diagnosed every year. It accounted for $4-5 \%$ of all malignancies in men and $2 \%$ of all malignancies in women [74,138], and accounted for $3 \%$ of all cancer deaths in men and $1 \%$ of all cancer deaths in women [138]. The morbidity from the disease usually results from the impairment of the inherent physiologic functions that usually take place in the head and neck region. This may include problems with breathing, swallowing, phonation, speech, olfaction and taste. However, the advancement in management strategies of oral squamous cell carcinoma, 
which includes significant loco-regional disease control, surgical reconstruction to restore these functions and rehabilitation, has significantly reduced these loco-regional morbidities. There has been a decline in the death rate till date due to the improved methods of diagnosis and treatment of oral cancers [73].The quality of life of these oral cancer patients has also improved as compared to the past, even in those who eventually succumbed to distant metastasis or the disease progression. Despite the advances in cancer therapies, it is only possible to achieve an improved survival time or cure rate in patients with early disease or NO neck if appropriate, optimal and adequate therapy is offered. However, the patients presenting with a late stage diseases are usually offered palliative therapies.

Only four randomized controlled trials were included in this meta-analysis $[46,79,157,169]$. The fact that only four studies have been successfully performed and published is a testament to the difficulties associated with well designed prospective randomized controlled trials in oral cavity cancers. Some of the problems associated with this kind of trials may include obtaining informed consent, uninfluenced allocation or randomization of patients into study groups, masking of investigators, study personnel and patients from the allocated intervention, adherence to the study protocol, and tracking or followup of patients and outcomes. Despite this small number, the evidence that favors elective neck dissection seems to be robust after the pooling effect of meta-analysis. The treatment modality of the primary tumor in all the studies was by surgical therapy except the study by Vandenbrouck et al where radiation therapy was used $[46,79,157,169]$. However, Ord et al have reported that the five-year survival rates in early stage (I and II) oral squamous cell carcinoma treated with either surgery or radiotherapy are similar [107].

For the primary outcome of this meta-analysis, disease-specific death rate was chosen as the most clinically meaningful endpoint to measure the benefit of elective neck dissection. Although homogeneity in the relative risk between studies was statistically indicated $(p=0.350)$, one still observed heterogeneity in the estimated disease-specific death rates within each treatment group. In the 
OBS group, these range from $11 \%$ to $42 \%$ and in the END group, from $12 \%$ to $30 \%$ (Table 2). This observed difference within each group might be due to the availability of more sophisticated investigative tools for the early identification of neck node metastasis with better sensitivity and specificity in recent times $[3,16,83,167,168]$. Some of the occult metastasis could now be better detected during evaluation and properly staged. For example, what would have been wrongly staged as NO in the past when these investigative tools were not available can now be better and correctly staged as N1 or N2 as the case may be during neck evaluation before primary therapy. This is evident in the most recent study by Yuen et al that showed a reduction in the incidence of diseasespecific death rate when compared to the other older studies within the OBS group (Table 2). In more than $60 \%$ of oral tongue carcinoma patients, diseaserelated death is due to uncontrolled neck disease [6]. However, the percentage of these deaths which can be attributed to the policy of watchful waiting or observation in patients with clinically NO neck is still unclear. It is also still very difficult to separately identify the actual deaths due specifically to neck pathology (nodal recurrences or metastases) from oral cancers.

The benefits of elective neck dissection in patients with oral cavity tumors with clinical N0 neck are still not clear because the results of numerous existing studies on the topic have been generally inconclusive. Most studies have failed to show statistically significant differences in survival outcome between the patients with oral cavity cancers with clinically NO neck in END and OBS groups $[40,46,157,169]$. However, there have been few studies which showed a significant survival benefit in favor of elective neck dissection in oral carcinoma patients with clinically NO neck [36,62,76,94,170]. Among prospective randomized trials, only the study by Kligerman et al showed evidence of a statistically significant disease-free survival benefit of elective neck dissection over a policy of observation [79] (Table 5 and Figure 4). However, this meta-analysis showed that being in the END group significantly reduced the risk of death due to the disease. It is possible that this observed pooled effect in the meta-analysis between END and OBS might have been largely influenced by the older studies. Perhaps, if similar studies are 
conducted now that there are better investigative tools to detect and better stage neck node metastasis, this observed difference may be absent.

In all the four studies, it was observed that the elective neck dissection markedly improved the regional control because fewer patients in the END group developed neck nodal recurrences or metastasis than those in the OBS group. In the END group, nodal recurrence was detected in $6 \%-30 \%$ of the patients while in the OBS group, nodal metastasis was detected in $37 \%-58 \%$ of the patients (Table 4). This may not really be a surprise as the patients in END group already had removal of the lymphatic and fibro fatty tissues in their neck. Hence, the use of neck node recurrence in the END group or metastasis in the OBS group as an outcome measure to advocate for neck dissection in oral cancers with clinical NO neck is not justifiable. This already existing bias is the reason why in this meta-analysis, neck node recurrence or metastasis was not considered as a primary outcome measure.

The patients whose necks were observed tended to have more regional recurrences $[40,138]$ and the results of the salvage treatment of the neck were generally poor $[37,40,46,76,81]$. Nodal metastasis has been considered a significant prognostic factor in oral cavity cancers and other head and neck malignancies $[6,13,118,135]$. Even when the tumor is small and considered to be an early stage, it is potentially aggressive and the incidence of neck node metastases is very high. Patients with T1NO and T2N0 squamous cell carcinoma of the oral cavity have been reported to have occult metastases in $13-33 \%$ and $37-53 \%$ respectively at the time of diagnosis $[7,21,62,118,152]$. This is similar to the findings from all the randomized controlled trials in this meta-analysis (Table 4). Only Vandenbrouck et al included T3NO patients in their study and this may actually explain the reason why they reported a higher rate of extra capsular nodal spread in their study than in other trials. Presence of capsular rupture has been demonstrated to be an ominous prognostic sign [157]. 
The depth or thickness of the primary tumor has been shown to be an important factor in neck metastasis, if the tumor depth exceeds $4 \mathrm{~mm}$, the risk of developing occult metastasis in the neck is increased to between $38-70 \%$ $[8,84,105]$. Tumor thickness is therefore an important pathologic factor to identify the patients at greater risk of developing neck node metastasis. Unfortunately, only Kligerman et al and Fakih et al in this meta-analysis considered checking for tumor thickness or depth hence, could not be examined for its impact on disease-specific death rate due to incomplete data $[46,79]$. However, their individual studies confirmed and showed a strong association of tumor thickness with loco-regional recurrences and survival. Fakih et al reported $92 \%$ occult metastases in patients with tumor thickness more than $4 \mathrm{~mm}$ who had elective neck dissection as against $33 \%$ in patients with tumor thickness less than $4 \mathrm{~mm}$ [46]. This value was a little bit higher than what other studies have reported $[8,84,105]$. The same study also showed a survival rate of $81 \%$ in patients with tumor depth of less than $4 \mathrm{~mm}$ as compared to $43 \%$ for those with tumor depth greater than $4 \mathrm{~mm}$ [46]. The thickness or depth of primary tumor is therefore an important determining index on whether or not to perform elective neck dissection in oral squamous cell carcinomas.

The lymphatic drainage of the oral cavity is commonly to the levels I, II and III $[6,26,66,162]$. Byers et al have reported finding "skip metastases" to lymph nodes in levels III and/or IV in $15.8 \%$ of the patients with cancer of the oral tongue and therefore recommended inclusion of the lymph nodes of level IV whenever an elective neck dissection is to be performed in any patient with cancer of the oral tongue [22]. However, Khafif et al reported that occult metastasis to lymph nodes in level IV from T1-T3N0 oral tongue cancer is very rare with an incidence of $4 \%$ and therefore, suggested extension of elective neck dissection to lymph nodes in level IV only when the intraoperative findings of metastases in levels II and III indicate an increased risk of tumor recurrence in the neck [77]. Shaha et al reported metastasis in nodes of the posterior triangle of the neck in $5 \%$ of patients with cancer of the oral cavity [134]. When the cancer is in the midline, bilateral neck metastasis can occur $[6,45]$. 
Metastases of the tongue carcinoma to the lingual lymph nodes have been documented [109].

All the studies except that by Kligerman et al reported no statistical survival benefit of elective neck dissection hence, did not recommend routine elective neck dissection for patients with clinically NO neck. They however suggested concurrent neck treatment with the surgical extirpation of the primary tumor if the tumor depth is more than $4 \mathrm{~mm}$ or if the patient cannot be regularly followed-up. However, a few retrospective studies have reported on the survival benefit of elective neck dissection in oral carcinoma with clinical N0 neck $[37,62,76,94]$. It has also been reported that the survival rate of patients with oral carcinomas will reduce by $50 \%$ once there is a palpable cervical lymph node $[42,52,87,132]$. In this meta-analysis, it was found out that elective neck dissection in oral carcinoma with NO neck can significantly reduce diseasespecific death rate and neck node recurrences. However, there was no significant survival benefit of elective neck dissection over the policy of waitand-watch/ observation/therapeutic neck dissection.

Carcinogenesis is a fundamental disorder of cellular growth control arising from prolonged exposure to physical or chemical mutagens. The accumulation of serial mutations in a cell's genes disrupts the normal growth and differentiation and gives the mutated cells a growth advantage over the surrounding host cells. Numerous chemicals have been implicated as mutagens in carcinogenesis. However, in the mechanism of cancer metastasis, a great deal of interplay exists among the putative chemical carcinogens, oncogenic viruses and tumor suppressor genes.

Tobacco and alcohol are important risk factors for the development of oral cancers. These carcinogens act synergistically and may increase the likelihood of developing cancer by up to 30 -folds $[35,67,85,144,159]$. Other environmental risk factors include irradiation, wood dust, nickel, chromium, chewing of tobacco, areca and betel nut, petrochemicals. Pre-malignant lesions like leukoplakia and erythroplakia have also been implicated. 
Viruses such as human papilloma virus (HPV), Epstein-Barr virus (EBV) and Human immunodeficiency virus (HIV) have also been implicated in carcinogenesis. The exact role of these viruses has not been fully elucidated, but some compelling associations have shown that they cause the activation of a proto-oncogene that induces cancer growth. HPV types 16 and 18 have been found to contribute to the in vivo malignant transformation of the keratinocyte $[64,93,103]$. HPV DNA is known to be closely associated with poorly differentiated cancers, positive lymph nodes and late-stage disease, which all indicate poor prognosis. Contradictory to this, patients with HPV positive squamous cell carcinomas of the oral cavity and other head and neck regions seem to have significantly improved response to chemotherapy and radiotherapy as compared with HPV-negative tumors [23,24,149]. The association of HPV and the development of inverted papilloma and recurrent respiratory papillomatosis and, the risk of transformation to carcinoma of the sinonasal region and larynx respectively have been well documented $[10,75,86]$. The strong association between undifferentiated nasopharyngeal carcinoma and EBV is well known $[47,59]$. Tobacco and alcohol are not risk factors for undifferentiated nasopharyngeal carcinoma, and there is no increased risk of second head and neck primary tumors from this site [31]. Immunosuppressed persons are at greater risk of developing malignancies. In human immunodeficiency virus (HIV) immunosuppression the most common oral cancers are Kaposi's sarcoma and non-Hodgkin's lymphoma. Squamous cell carcinoma has also been reported to be associated with HIV infection $[29,44,120]$.

Advances in molecular biology have revolutionized the ability to investigate the specific genetic mutations responsible for the evolution of malignant cells. Specific genetic elements that suppress cancer growth called tumor suppressor genes have been described. The p53 gene, located on chromosome 17p, is one of the most intensely studied tumor suppressor genes and its abnormality has been reportedly associated with the development of head and neck squamous cell carcinoma $[14,51,93,114,129]$. Its mechanism of action differs from the viral-induced carcinogenesis model in that it is the loss of one or both 
alleles of a tumor suppressor gene that induces cancer growth rather than the activation of proto-oncogenes.

The HPV types 16 and 18 produce two proteins, E6 and E7, which directly increase the proliferative life span of keratinocytes [64,103] and indirectly encourage the proliferation by binding the proteins of tumor suppressor genes p53 and RB-1 [70]. E6 and E7 are also involved in the degradation of p53 $[33,164]$. As previously mentioned, smoking is associated with an increase in the likelihood of developing head and neck squamous cell carcinoma. Molecular genetic studies have shown that the frequency of fragile sites on chromosome Ilq13 is significantly higher in peripheral blood lymphocytes of smokers than those of nonsmokers [11,100,165]. Chromosome Ilq13 amplification is found in one third to one half of head and neck tumor specimens and associated with a high histologic grade in those specimens $[11,165]$. The amplification of $l l q 13$ is associated with a poor prognosis in patients with head and neck squamous cell carcinoma [100].

After the primary tumor has established itself in the mucosa, the first step in the mechanism of cancer metastasis is breach of the basement membrane $[153,171]$. The basement membrane is composed primarily of type IV collagen, which forms the structural scaffolding of the basement membrane, laminin, and proteoglycans. The destruction of these components of the basement membrane by hydrolases elaborated by the tumor allows the local, regional, and distant movement of the tumor cells [13]. These hydrolases include urokinase- type plasminogen activator, several collagenases, and stromalysins. Urokinase-type plasminogen activator activates plasmin, which degrades laminin. Plasmin also controls the production of type IV collagenase, which degrades type IV collagen. Type I collagenase degrades type I collagen (fibrillar collagen), which makes up most of the extracellular matrix [13]. The amplification of segments of chromosome llq13 can result to changes in the tumor cell cytoskeleton which, in turn, can lead to an increase in the cell's metastatic potential [28]. 
The mode of cancer spread is in three main ways. The first is direct extension from the primary site to adjacent areas. The second is spread through the lymphatic channels to lymph nodes. The third is spread through the blood vessels to distant sites in the body. In oral cavity cancers and other head and neck cancers, a spread to the lymph nodes in the neck is relatively common.

Before gaining access to the circulation, tumor cells or groups of tumor cells must dislodge from the primary tumor and survive in neck lymph nodes. This is the beginning of metastatic neck node. The filter and barrier function of the lymph node appears to be effective at the initial stage, as lymphatic spread is generally limited initially to the first echelon of lymph nodes $[26,65]$. As a lymph node is progressively replaced by metastatic tumor, the local lymphatic flow may be distorted, reflected and perhaps reversed, directing new lymph borne tumor cells to fresh nodes. The cancerous node itself may act as a focus for further tertiary spread $[28,153]$. The blood circulation (blood more so than lymph) is a hostile environment for cancer cells, and most cells released into the circulation die before they successfully exit the circulation [28]. Finally, once the tumor cells have successfully exited the circulation, they must invade the new tissue and survive in the new location. There is interplay among mechanical factors and other host-tumor interactions which control secondary tumor survival and growth. 
Figure 6: Sequence of Metastasis (Source: Cancer of the head and neck [147])
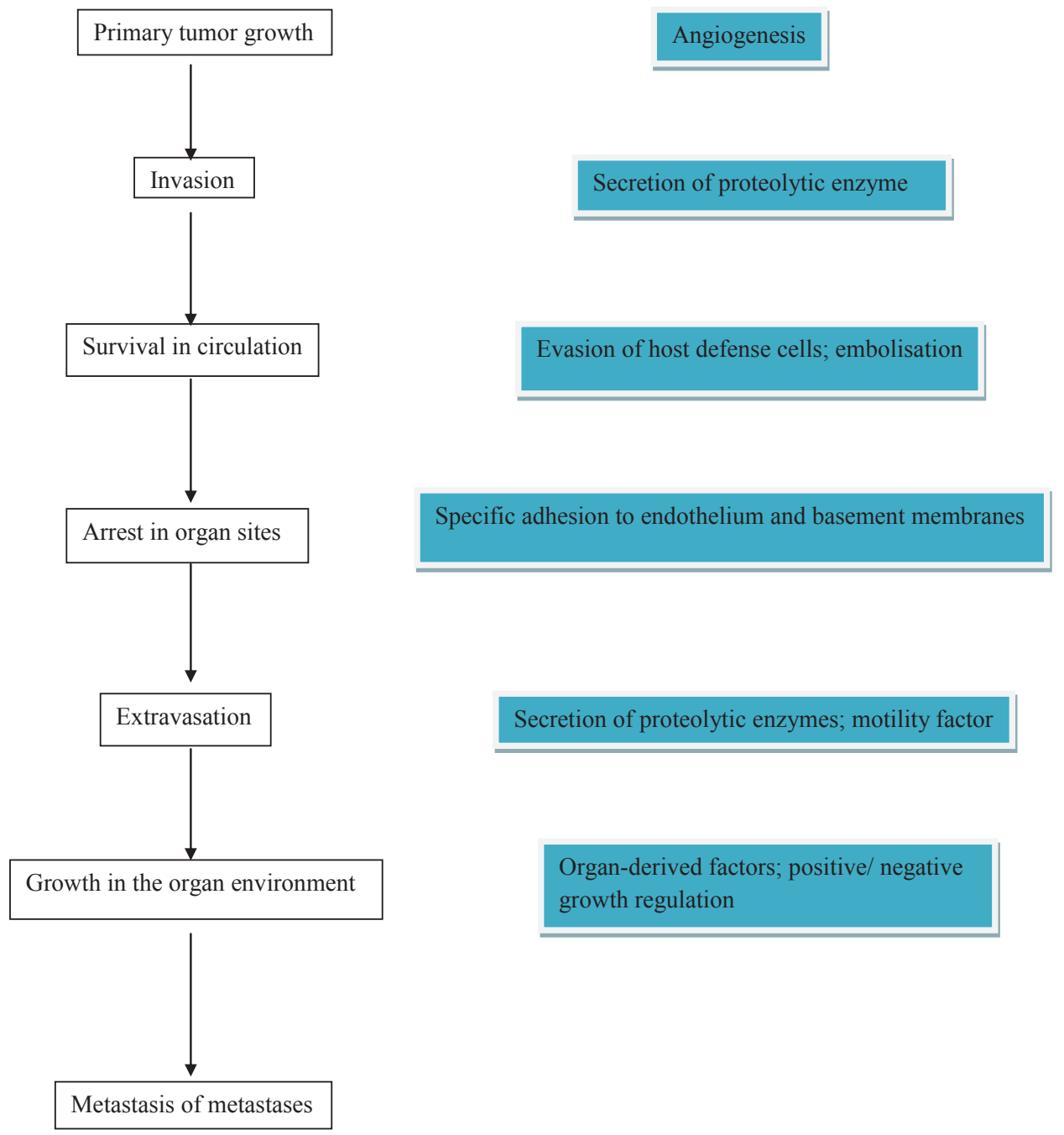

Secretion of proteolytic enzymes; motility factor

Organ-derived factors; positive/ negative growth regulation 
The extent of treatment of oral cavity cancers depends on the extent of the primary tumor, presence of locoregional spread or distant metastases and presence of intercurrent medical disease. These factors also contribute to the survival outcome of such patients. The treatment modalities for oral carcinomas may include surgery, radiotherapy, chemotherapy, combination of any of these modalities and biologic therapy (only in few centers) [106,110]. The latest National Comprehensive Cancer Network (NCCN) practical guideline recommended that most oral cancers be treated by concurrent chemo radiotherapy (CCRT), rather than by surgery with or without adjunct therapy. In fact, surgery is being viewed as the equivalent of definite radiotherapy (RT) for only T1-2, N0-1 cancers. This guideline implies that the treatment outcomes of RT and CCRT are better than or equivalent to that of surgery with or without adjunct RT, which is the traditional treatment protocol. The 3-year disease free survival rate using primary radiation therapy is about $85 \%$ for T1N0 oral carcinoma and $64 \%$ for T2N0 oral carcinoma, similar to surgical treatment [88]. In the randomised controlled trials in this meta-analysis, the disease free survival rates are as shown in Table 5. Vandenbrouck et al however reported a value of $46 \%$ when interstitial iridium was used to treat the primary oral tumors [157]. This supported the findings by Wang that cone electron beam boost technique provides a superior cure rate when compared to interstitial implant for early stage oral carcinoma [161]. However, one of the problems of using radiotherapy as curative treatment for oral cavity tumor is the proximity of the mandibular arch. Notwithstanding, the choice of modality of treatment of the primary oral carcinoma depends on the protocol of treatment in different centers. However, when the primary tumor is being treated with surgery, elective neck dissection may be carried out and when radiotherapy is being used to treat the primary tumor, elective irradiation of the neck is performed [47]. However, the five-year survival rates are similar in early stage oral squamous cell carcinoma treated with either surgery or radiotherapy [107].

Oral squamous cell carcinoma results from the accumulation of genetic and tissue damage in a field exposed to a carcinogen. This process can be interrupted or reversed through the use of natural or synthetic agents, defined 
as chemoprevention [111]. However, in established cases of oral carcinomas or other head and neck cancers, chemotherapy has been demonstrated to play a significant role in their management $[43,115,128,148]$. Chemotherapy is the use of anti-cancer (cytotoxic) drugs to destroy cancer cells. They work by disrupting the growth of cancer cells. Chemotherapeutic agents have a role in the palliative treatment of oral squamous cell carcinomas or in people whose cancers have spread to other parts of their body or whose cancers have come back after radiotherapy or surgical therapy.

The use of chemotherapy alone has been shown not to have any evidence of increased survival [57] hence, not recommended. In general, chemotherapy for oral squamous cell cancer has been used in three settings: as neoadjuvant or induction chemotherapy before locoregional treatment with surgery or radiation, as adjuvant post-op chemotherapy usually with radiation or as concurrent chemoradiotherapy for advanced disease with an intention of down staging the tumor [1,2,5,9]. Currently used agents include cisplatin, carboplatin, 5fluorouracil and the taxanes (paclitaxel and docetaxel). The 5-fluorouracil and taxanes are also regarded as radiation sensitizers [125]. Recent interest has been shown in intra-arterial delivery of chemotherapy, which increases the drug dose to the tumor and decreases systemictoxicity [125]. Neoadjuvant chemotherapy has not been shown to improve survival rates $[57,63]$ and few data exist on adjuvant chemotherapy after radiation therapy. The use of concurrent chemotherapy and radiation therapy has been shown to increase survival rates in patients with oral cancers and other head and neck cancers $[43,148]$. Unfortunately, most series have combined all head and neck sites, and it is difficult to interpret data for the oral cavity alone when sites such as the larynx, oropharynx and nasopharynx (which are very sensitive to chemoradiation therapy) are included. However, patients who have more extensive cancers are often treated with concurrent chemotherapy and radiation therapy. Studies have shown that chemotherapy given at the same time as radiation therapy is more effective than if it is given before or after a course of radiation therapy $[43,115,128,148]$. 
Radiotherapy (RT) involves the delivery of a precise radiation dose to the location of a malignant tumor or specific areas within the tumor to destroy the cancer cells. The careful treatment planning allows the surrounding normal tissues to be spared. It can be the only treatment in some early stage oral cancers and can be used as adjunct to chemotherapy or surgery to destroy small areas of cancer that could not be removed by the surgery. Elective irradiation of the NO neck can also be performed in early stage oral cancer. Radiotherapy in the form of external beam therapy (EBT) or intensity modulated radiation therapy (IMRT) has been used to treat oral cancers and other head and neck cancers [20]. Brachytherapy can also be the mode of treatment [157]. The control rates of $86 \%$ for T1 and $75 \%$ for T2 oral cavity carcinoma by radiotherapy have been reported [88]. However, treatment with implants radiation has been associated with significant complications. About $17 \%$ of the T1 lesions and almost $50 \%$ of the T2 lesions had soft-tissue necrosis when treated with iridium $\left(\operatorname{Ir}^{192}\right)$ implants [25]. Wang has reported that the intraoral cone electron beam boost technique provides a superior cure rate compared to interstitial implant for T1 and T2 oral cancers [161]. When external beam radiation is the chosen treatment modality for oral carcinoma with N0 neck, National Comprehensive Cancer Network (NCCN) has recommended a total dose of 70Gy to primary tumor and $\leq 50 \mathrm{~Gy}$ to the neck at risk of occult metastasis. Both chemotherapy and radiotherapy may be associated with complications and this may be more marked in instances of poor pre-treatment evaluation and preparation $[2,5,9,19]$.

The role of surgery as a single or combined therapy in the primary oral cancers treatment has been well documented. Although the outcome of radiotherapy and surgical treatment of oral carcinoma with clinical NO neck is similar [107], some surgeons prefer surgery because it has the advantages of short term duration of treatment, low cost and proper staging of the tumor [6]. The surgical excision of the tumor may be performed with either laser or cold knife. However, issues have been raised concerning laser versus conventional excision of these lesions with cold knife or scalpel. The methodology is purely a technical choice, since the survival rate of about $80 \%$ for oral carcinoma with 
clinically NO neck does not change according to technique. Laser provides no distinct oncologic advantages over a standard surgical scalpel. However, it is very important for cure to have at least $1 \mathrm{~cm}$ free tumor excision margin during surgery [143]. Metastasis of oral squamous cell carcinoma into the lymph nodes of the neck is common and reduces survival of the patient. It may therefore be necessary to include neck dissection in the complete surgical treatment of some of these patients. In instances of large oral cavity defect following tumor excision and not permitting direct primary closure, reconstruction with pedicle (such as pectoralis major, latissimus dorsi) or free micro vascular (such as radial forearm, latissimus dorsi, periscapular and antero-lateral thigh) myocutaneous flaps can be used $[98,131,143]$.

Biological therapy or immunotherapy is a type of therapy which utilizes the biological response modifiers (BRM) to boost the body immune system and enable it to directly or indirectly fight cancer cells. Although not specific for oral cavity cancers, it has been shown to reduce or control the side effects being experienced from other treatments like chemotherapy and radiotherapy. In future, this therapy may become relevant in the management of oral cancers with N0 neck. These biological response modifiers occur naturally in the body but they can also be produced in the laboratory [72,78]. These agents include interferons, interleukins, colony-stimulating factors, monoclonal antibodies, vaccines, gene therapy and nonspecific immune-modulating agents. Their exact mechanism of action is not fully known but they are thought to boost the power of the immune system to destroy or kill cancer cells such as T cells, NK cells and macrophages, make cancer cells more recognizable by the immune system, stop the process which changes normal cells to cancer cells, enhance the body system to repair or replace damaged normal cells and also keep the cancer cells from spreading to other parts of the body $[72,78,89]$.

Although elective neck dissection has been shown to reduce disease specific death rate and nodal recurrences in this study, it is not without morbidity and complications. It is therefore imperative that surgeons should pay close attention to their techniques so as to minimize the morbidities. The 
complications that can arise from neck dissection include haemorrhage, air embolism, pneumothorax, chyle leak, facial edema, cervical fistula, limitation of shoulder movement (Frozen shoulder), paresthesia, and chronic neck and shoulder pain and carotid blow out $[49,60,69,139]$.

The policy which advocates on the prevention of oral cavity cancer should be encouraged, promoted and supported. This is because prevention is usually better than cure, reducing economic loss, morbidity and death from the disease. Although the exact cause of oral carcinoma is unknown, it is expected that if exposure to the risk factors can be avoided, there may be a significant reduction in the incidence of oral cancer. Alcohol, cigarette, tobacco, areca or betel nuts are known risk factors for oral cancers. Social habits which discourage exposure to these risk factors may reduce the occurrence of oral cancer. Unfortunately, oral cancers have been reported in patients without exposure to these risk factors and others [62]. Plummer-Vinson syndrome has been associated with an increased risk of cancer of the oral cavity [6]. Larsson et al found out that an increased number of patients with this syndrome in part of Sweden accounted for the high rates of cancer of the oral cavity in females, and as the high rates of this syndrome have fallen in Sweden, so too has the incidence of oral cancer. In regions where hook worm infestation is rampant, the use of antihelminthics may also be protective against oral cancer as hook worm can cause chronic iron deficiency anaemia. Few reports exist on diet which may protect against oral cancers $[90,93]$. This includes eating of diet rich in fresh fruits and vegetables [91,94]. Epidemiologic evidence has suggested that vitamins $A, C$ and carotenoids (present in fruits and vegetables) may be protective against epithelial cancers [91,94]. A decreased risk of oral cancer associated with vitamin $A$ and $C$ intake has been reported [6]. Also, consumption of trace elements and antioxidant vitamins has also been reported to be protective against development of oral cancers [94].

After the primary treatment of oral cancer patients, they must be followed up in other to detect any recurrence early. National Comprehensive Cancer Network (NCCN) has recommended that during follow-up, the patients must be asked if 
they have noticed any new developments or complaints and physical examinations of the patients must be performed every $1-3$ months in the $1^{\text {st }}$ year; every $2-4$ months in the $2^{\text {nd }}$ year, every $4-6$ months in the $3^{\text {rd }}$ to $5^{\text {th }}$ year and every $6-12$ months after 5 years of primary treatment. Chest imaging as clinically indicated must be performed or every 6 months. Also, thyroid function test especially to evaluate thyroid stimulating hormone (TSH) must be performed at least once in a year if the neck is irradiated. Speech, hearing and swallowing must be evaluated and rehabilitation carried out as indicated. Patients must be counselled on cessation from social habits like smoking of cigarette, chewing of tobacco, betel or areca nut and drinking of alcohol. Dental follow-up is also recommended. 


\section{Summary}

There is no greater controversy on the management of oral cancers than the optimal treatment for clinical NO necks. Researchers have however demonstrated that these clinical NO neck have shown evidence of occult metastases in about $30 \%$ or higher, depending on the size, site of primary tumor and the histological diagnostic methods. The greatest challenge that is being faced by the head and neck oncologists and surgeons is the correct identification of the subset of these patients with cervical nodal micro metastases that will require elective neck treatment. Clinical palpation of the neck is grossly inadequate. Although the available radiological investigative tools have shown some improvement in the detection of neck metastasis but the sensitivity rates have been reported to be in the range of about $70-80 \%$. Despite the increase in knowledge and advancement in cancer management, there is still no method to determine correctly the real micro metastatic disease free neck. Although squamous cell carcinoma of head and neck regions is a locally aggressive disease with a great tendency for loco-regional and distant metastasis, researchers have shown that not all the head and neck tumors metastasize, especially at the early stage. Treating the neck which is actually node negative means incurring unnecessary costs, prolong hospital stay and causing avoidable morbidity. However, when the neck is not included in the management plan for the primary tumor in a clinically NO neck but with unidentified micro metastases, the implication of this is poor treatment outcome with increased morbidity and mortality rate.

The reality is that some patients with a clinical NO neck indeed have no cancer cells in the cervical lymphatics and their neck must not be over treated. In employing proper oncologic therapy for the neck, one must balance the desire to preserve the present function of the neck with the wish to prevent future morbidity or loss of neck function. This requires that all persons involved in the multimodality treatment of oral carcinomas; surgeons, radiation oncologists, and medical oncologists must have a unified therapeutic modality that may 
achieve the desired goal, while minimizing morbidity. Although there are many available retrospective studies on oral cancers patients with clinical NO necks and modalities of therapies but there is no consensus on the unique therapeutic approach. The benefits of elective neck dissection in patients with early oral cavity tumors have remained obscure. Few prospective studies are available but there is still inconclusive evidence on whether elective neck dissection is of any value over therapeutic neck dissection in oral cancers with NO neck. A systematic review of prospective randomized controlled trials is needed to answer these questions owing to the inherently biased nature of the available studies. Only few of such randomized controlled trials are available in the literature and none of these studies have a study population above eighty patients. This study therefore systematically reviewed the existing published randomized controlled trials on the unresolved questions of elective versus therapeutic neck dissection in the clinically NO neck of oral carcinoma and performed a meta-analysis of their data. The PRISMA (Preferred Reporting Items for Systematic reviews and Meta-Analyses) guideline for randomized trials was followed.

The objectives were to evaluate the effectiveness of elective neck dissection in the successful reduction of neck node recurrence in oral carcinomas with clinically NO neck, to determine and compare the disease-specific death rate of elective neck dissection to the policy of observation in early oral squamous cell carcinoma with NO neck and to compare the survival outcome of elective neck dissection to the policy of observation in oral squamous cell carcinomas.

Out of the 613 studies identified during the comprehensive search, only 4 randomized controlled trials met the criteria and were included in the metaanalysis. The total number of patients from the studies was 283. All the studies had their patients randomized into two groups; END group and OBS group. There was no statistical difference between these two groups in terms of sex and age of patients, histologic type and staging. All the trials reported on the 
patients' pathologic distributions, neck recurrences and metastasis, survival and death outcome and follow-up.

Despite the intention to include other factors as the primary outcome measures in this meta-analysis, the only clinically meaningful endpoint to measure the outcome benefit of elective neck dissection is the disease-specific death rate. The meta-analyses of these studies showed that elective neck dissection can effectively reduce the risk of death from the disease (disease-specific death) thereby, increasing the chance of survival \{Fixed effect model RR $=0.57,95 \%$ $\mathrm{Cl}$ of $0.36-0.89, \mathrm{p}=0.014\}$ or $\{$ Random effects model $\mathrm{RR}=0.59,95 \% \mathrm{Cl}$ of 0.37 - 0.96, $p=0.034\}$. It is possible that this observed pooled effect in the metaanalysis between END and OBS might have been largely influenced by the older studies. Perhaps, if the studies are conducted now that there are better investigative tools to identify and better stage neck node metastasis, this observed difference may be absent.

There was also a significant evidence of reduction in neck nodal recurrences when elective neck dissection was performed. A few retrospective studies have reported on the survival benefit of elective neck dissection in early stage oral carcinoma. Only the study by Kligerman et al from this systematic review showed statistical significant evidence of disease-free survival rates benefit of elective neck dissection over observation. However, this systematic review did not show any significant survival outcome benefit of elective neck dissection over the policy of observation.

In conclusion, the benefits of statistical significant reduction in disease-specific death rates and neck node recurrences may justify the need for elective neck dissection in oral carcinomas with clinically NO neck. 


\section{$7 \quad$ Zusammenfassung}

Die optimale Behandlung des klinischen NO Halses bei Mundhöhlenkarzinomen wird in der Literatur kontrovers diskutiert. Je nach Größe und Lage des Primärtumors sowie der Histologie liegt die okkulte Metastasierungsrate bei Patienten mit klinischem N0-Hals bei circa 30\%. Kopf-Hals-Onkologen und Chirurgen stehen daher vor der Herausforderung, die Untergruppe der Patienten mit zervikalen, nodalen Mikrometastasen zu identifizieren, die einer elektiven Neck dissection zugeführt werden sollten. Die alleinige Palpation ist zur Bestimmung des Lymphknotenstatus absolut unzureichend. Die Sensitivitätsraten der bildgebenden Verfahren liegen trotz Verbesserungen in den letzten Jahren jedoch weiterhin nur bei 70 - 80\%. Trotz der Zunahme an Wissen und Fortschritt in der Krebstherapie gibt es noch keine Methode zur korrekten Bestimmung der tatsächlichen Metastasierungssituation im Bereich des Halses. Obwohl Plattenepithelkarzinome des Kopf-Hals-Bereiches eine große Neigung zur Bildung von locoregionären und distanten Metastasen haben, konnten verschiedene Studien zeigen, dass vor allem Tumore in frühen Stadien häufig nicht metastasieren. Die Operation von Patienten ohne manifeste Lymphknotenmetastasen führt zu unnötigen Kosten, einer Verlängerung des Krankenhausaufenthalts und vermeidbaren Komorbiditäten. Wird der Hals jedoch nicht in das Therapiekonzept miteinbezogen obwohl nicht identifizierte Mikrometastasen vorliegen, kann dies zu einem unvorteilhaften Behandlungsergebnis mit erhöhter Morbidität und Mortalität führen.

Die Realität ist, dass bei einigen Patienten mit klinischem N0-Hals keine Lymphknotenmetastasen bestehen und diese Patienten nicht überbehandelt werden dürfen. Die optimale onkologische Therapie der Halslymphknoten muss daher zum Ziel haben, die Funktion zu erhalten und die Morbidität nach Möglichkeit zu minimieren, was eine multidisziplinäre Behandlung erfordert.

Obwohl viele retrospektive Studien zu oralen Karzinomen mit klinischen N0Hals und deren Therapiemodalitäten vorliegen, gibt es keinen Konsens über die optimale Therapie und den etwaigen Nutzen einer elektiven Neck 
dissection bei Patienten mit Mundhöhlenkarzinomen und N0-Hals. Es gibt in der Literatur nur wenige prospektive Studien zu diesem Thema und es gibt bisher keine Evidenz, ob eine elektive Neck dissection einer therapeutischen Neck dissection bei Patienten mit Mundhöhlenkarzinomen und NO-Hals überlegen ist. Eine systematische Analyse der vorliegenden prospektiven, randomisierten, kontrollierten Studien ist daher erforderlich, um diese Frage zu beantworten. Insgesamt gibt es nur wenige randomisierte, kontrollierte Studien und keine dieser Studien hat eine Patientenpopulation über 80 Patienten untersucht.

Die vorliegende Analyse untersuchte systematisch publizierte randomisierte, kontrollierte Studien hinsichtlich ungelöster Fragen zur elektiven Neck dissection versus therapeutischen Neck dissection bei Patienten mit oralen Karzinomen und klinischem NO-Hals und erstellte eine Metaanalyse ihrer Daten. Die Studie folgte den PRISMA-Leitlinien (Preferred Reporting Items for Systematic reviews and Meta-Analyses).

Das Ziel dieser Arbeit war, die Wirksamkeit der elektiven Neck dissection hinsichtlich der Verringerung von Lymphknotenrezidiven bei Patienten mit oralen Karzinomen mit klinischem NO-Hals zu evaluieren und die krankheitsspezifische Mortalität sowie das Überleben von Patienten nach elektiver Neck dissection gegenüber Patienten, die keine Neck dissection erhielten, zu bestimmen und zu vergleichen.

Aus 613 Studien, die während der umfassenden Suche identifiziert wurden, erfüllten nur 4 randomisierte, kontrollierte Studien die Einschlusskriterien und wurden in die Meta-Analyse eingeschlossen. Die Gesamtzahl der Patienten aus den Studien betrug 283. In allen Studien waren die Patienten in zwei Gruppen randomisiert: Elektive Neck dissection (END)-Gruppe und Observation (OBS)-Gruppe. Es gab keinen statistischen Unterschied zwischen diesen beiden Gruppen in Bezug auf Geschlecht und Alter der Patienten, histologischen Typ und Staging. Alle Studien untersuchten histologische 
Entität, Rezidive im Bereich des Halses, Metastasen, Überleben und FollowUp.

Trotz der Absicht, andere Faktoren als primäre Zielparameter in dieser MetaAnalyse zu erfassen, ist der einzige klinisch bedeutungsvolle Endpunkt, um den Nutzen der elektiven Neck dissection zu messen, die krankheitsspezifische Mortalität. Die Meta-Analyse dieser Studien zeigte, dass die elektive Neck dissection die krankheitsspezifische Mortalität signifikant reduzieren kann und damit das Überleben verbessert \{Fixed Effects-Modell $\mathrm{RR}=0,57,95 \% \mathrm{Cl}$ von $0,36$ bis $0,89, p=0,014\}$ oder $\{$ Random Effects-Modell $R R=0,59,95 \% \mathrm{Cl}$ von $0,37$ bis $0,96, p=0,034\}$. Es ist jedoch möglich, dass dieser beobachtete Unterschied zwischen OBS- und END-Gruppe durch das Alter der Studien beeinflusst wurde und nicht zu beobachten wäre, wenn die Studien heute mit den neuesten Untersuchungsmethoden durchgeführt worden wären.

Zusätzlich konnte gezeigt werden, dass die Durchführung einer elektiven Neck dissection das Risiko eines Lymphknotenrezidivs verringert. Eine verbesserte Überlebensrate nach elektiver Neck dissection bei Patienten mit frühen Stadien oraler Karzinome wurde ebenfalls in einigen retrospektiven Studien berichtet. Nur die Studie von Kligerman et al. [79] aus dieser systematischen Übersichtsarbeit zeigte einen statistisch signifikanten Nutzen der elektiven Neck dissection gegenüber engmaschiger Kontrolle hinsichtlich des krankheitsfreien Überlebens. Die systematische Übersichtsarbeit zeigte jedoch keinen signifikanten Vorteil der elektiven Neck dissection gegenüber wait-andsee hinsichtlich des Überlebens. Zusammenfassend kann festgehalten werden, dass die statistisch signifikante Verringerung der krankheitsspezifischen Mortalität und Lymphknotenrezidivrate die Notwendigkeit einer elektiven Neck dissection bei Patienten mit Mundhöhlenkarzinomen und klinischem NO-Hals rechtfertigen. 


\section{References}

1. Adelstein DJ, LeBlanc M. Does Induction Chemotherapy Have a Role in the Management of Locoregionally Advanced Squamous Cell Head and Neck Cancer? JCO 2006;24:2624-8.

2. Agarwala SS. Adjuvant chemotherapy in head and neck cancer. Hematol Oncol Clin North Am 1999;13:743-52.

3. Akoglu E, Dutipet M, Bekis R, Degirmenci B, Ada E, Guneri A. Assessment of cervical lymph node metastasis with different imaging methods in patients with head and neck squamous cell carcinoma. $J$ Otolaryngol 2005;34:384-94.

4. Ali S, Tiwari RM, Snow GB. False positive and false negative neck nodes. Head Neck Surg 1985;8:78-82.

5. Al-Sarraf M, Reddy MS. Nasopharyngeal carcinoma. Curr Treat Options Oncol 2002;3:21-32.

6. Alvi A, Myers EN, Johnson JT. Cancer of the Oral Cavity. In: Myers EN, Suen JY. Editors. Cancer of the head and neck. $3^{\text {rd }}$ eds. WB Saunders Company: Philadelphia, Pennsylvania. 1996:321-60.

7. Andersen PE, Cambronero E, Shaha AR, Shah JP. The extent of neck disease after regional failure during observation of the NO neck. Am J Surg 1996;172:689-91.

8. Asakage T, Yokose T, Mukai K, Tsugane S, Tsubono Y, Asai M, Ebihara $\mathrm{S}$. Tumor thickness predicts cervical metastasis in patients with stage 1/11 carcinoma of the tongue. Cancer 1998;82:1443-8.

9. Barlett EICC. Neck dissections. Surg Clin North Am 1926;6:481-505.

10. Baumann JL, Cohen S, Evjen AN, Law JH, Vadivelu S, Attia A, Schindler JS, Chung CH, Wirth PS, Meijer CJ, Snijders PJ, Yarbrough WG, Slebos RJ. Human papillomavirus in early laryngeal carcinoma. Laryngoscope 2009;119:1531-7. 
11. Berenson JR, Yang J, Mickel RA. Frequent amplification of the bel-1 locus in head neck squamous cell carcinomas. Oncogene 1989;4:11116.

12. Bocca E, Pignataro O, Oldini C, Cappa C. Functional neck dissection: an evaluation and review of 843 cases. Laryngoscope 1984;94:942-45.

13. Boyd D. Invasion and metastasis. Cancer Metastasis Rev 1996;15:7789.

14. Brash DE, Rudolph JA, Simon JA, Lin A, McKenna GJ, Baden HP, Halperin AJ, Ponten J. A role for sunlight in skin cancer: W-induced p53 mutations in squamous cell carcinoma. Proc Natl Acad Sci U S A 1991;88:10124-8.

15. Brazilian Head and Neck Cancer Study Group. End results of a prospective trial on elective lateral neck dissection vs type III modified radical neck dissection in the management of supraglottic and transglottic carcinomas. Head Neck 1999;21:694-702.

16. Brazilian Head and Neck Cancer Study Group. Results of a prospective trial on elective modified radical classical versus supraomohyoid neck dissection in the management of oral squamous carcinoma. Am J Surg 1998;176:422-7.

17. Brennan JA, Mao L, Hruban RH, Boyle JO, Eby YJ, Koch WM, Goodman SN, Sidransky D. Molecular assessment of histopathological staging in squamous cell carcinoma of the head and neck. $\mathrm{N}$ Engl J Med 1995;332:429-35.

18. Brennan JA, Sidransky D. Molecular staging of head and neck squamous carcinoma. Cancer Metastasis Rev 1996;15:3-10.

19. Burlage FR, Roesink JM, Kampinga HH, Coppes RP, Terhaard C, Langendijk JA, van Luijk P, Stokman MA, Vissink A. Protection of salivary function by concomitant pilocarpine during radiotherapy: a double-blind, randomized, placebo-controlled study. Int J Radiat Oncol Biol Phys 2008;70:14-22.

20. Butlin. Diseases of the Tongue. Cassell \& Co. 1885. 
21. Byers RM, El-Naggar AK, Lee YY, Rao B, Fornage B, Terry NH, Sample D, Hankins P, Smith TL, Wolf PJ. Can we detect or predict the presence of occult nodal metastases in patients with squamous cell carcinoma of the oral tongue? Head Neck 1998;20:138-44.

22. Byers RM, Weber RS, Andrews T, McGill D, Kare R, Wolf P. Frequency and therapeutic implications of 'skip metastases' in the neck from squamous cell carcinoma of the oral tongue. Head Neck 1997;19:14-19.

23. Campisi G, Panzarella V, Giuliani M, Lajolo C, Di Fede O, Falaschini S, Di Liberto C, Scully C, Lo Muzio L. Human papillomavirus: its identity and controversial role in oral oncogenesis, premalignant and malignant lesions. Int J Oncol 2007;30:813-823.

24. Castro T, Bussoloti Filbo I. Prevalence of human papillomavirus (HPV) in oral cavity and oropharynx. Braz J Otorhinolaryngol 2006;72:272-82.

25. Cataldo E, Less WC, Giunta JL. Squamous odontogenic tumor: a lesion of the periodontium. J Periodontol 1983;54:731-5.

26. Civantos FJ, Stoeckli SJ, Takes RP, Woolgar JA, de Bree R, Paleri V, Devaney KO, Rinaldo A, Silver CE, Mondin V, Werner JA, Ferlito A. What is the role of sentinel lymph node biopsy in the management of oral cancer in 2010? Eur Arch Otorhinolaryngol 2010;267:839-44.

27. Close LG, Merkel M, Vuitch MF, Reisch J, Schaefer SD. Computed tomographic evaluation of regional lymph node involvement in cancer of the oral cavity and oropharynx. Head Neck 1989;11:309-17.

28. Collins SL. Controversies in management of cancer of the neck. In: Thawley SE, Panje WR, Batsakis JG, Lindberg RD. Editors. Comprehensive Management of Head and Neck Tumors. WB Saunders Co: Philadelphia. 1987:1386-443.

29. Conant MA, Volberding P, Fletcher V, Lozada FI, Silverman S Jr. Squamous cell carcinoma in sexual partner of Kaposi's sarcoma patient. Lancet 1982;1:286. 
30. Constantinides MS, Rothstein SG, Persky MS. Squamous cell carcinoma in older patients without risk factors. Otolaryngol Head Neck Surg 1992;106:275-7.

31. Cooper JS, Scott C, Marcial V, Griffin T, Fazekas J, Laramore G, Hoffman A. The relationship of nasopharyngeal carcinomas and second independent malignancies based on the Radiation Therapy Oncology Group experience. Cancer 1991;67:1673-7.

32. Crile G. Excision of cancer of the head and neck. JAMA 1906;47:1780-6.

33. Crook J, Mazeron JJ, Marinello G, Martin M, Raynal M, Calitchi E, Faraldi M, Ganem G, Le Bourgeois JP, Pierquin B. Combined external irradiation and interstitial implantation for T1 and T2 epidermoid carcinomas of base of tongue: the Creteil experience (1971-1981). Znt J Radiat Oncol Biol Physiol 1989;15:105-14.

34. de Bondt RB, Nelemans PJ, Hofman PA, Casselman JW, Kremer B, van Engelshoven JM, Beets-Tan RG. Detection of lymph node metastases in head and neck cancer: a meta-analysis comparing US, USgFNAC, CT and MR imaging. Eur J Radiol 2007;64:266-72.

35. Decker J, Goldstein JC. Current concepts in otolaryngology: risk factors in head and neck cancer. N Engl J Med 1982;306:1151-5.

36. DerSimonian R, Laird N. Meta-analysis in clinical trials. Controlled Clin Trials 1986;7:177-88.

37. Dias FL, Kligerman J, Matos de Sá G, Arcuri RA, Freitas EQ, Farias T, Matos F, Lima RA. Elective neck dissection versus observation in stage I squamous cell carcinomas of the tongue and floor of the mouth. Otolaryngol Head Neck Surg 2001;125:23-9.

38. DiNardo LJ. Lymphatics of the submandibular space: an anatomic, clinical, and pathologic study with applications to floor-of-mouth carcinoma. Laryngoscope 1998;108:206-14.

39. Don D, Yoshimi A, Lufkin R, Fu Y, Calcaterra T. Evaluation of cervical lymph node metastasis in squamous cell carcinoma of the head and neck. Laryngoscope 1995;105:669-74. 
40. Duvvuri U, Simental Jr AA, D’Angelo G Johnson JT, Ferris RL, Gooding W, Myers EN. Elective neck dissection and survival in patients with squamous cell carcinoma of the oral cavity and oropharynx. Laryngoscope 2004;114:2228-34.

41. Edge SB, Byrd DR, Compton CC, Fritz AG, Greene FL, Trotti A. Editors. AJCC Cancer Staging Manual. 7th eds. Springer: New York. 2010.

42. Eiband JD, Elias EG, Suter CM, Gray WC, Didolkar MS. Prognostic factor in squamous cell carcinoma of the larynx. Am J Surg 1989;158:314-7.

43. El-Sayed S, Nelson N. Adjuvant and adjunctive chemotherapy in the management of squamous cell carcinoma of the head and neck region: a meta-analysis of prospective and randomized trials. J Clin Oncol 1996;14:838-47.

44. Epstein JB, Silverman S Jr. Head and neck malignancies associated with HIV infection. Oral Surg Oral Med Oral Pathol 1992;73:193-200.

45. Fagan JJ, Collins B, Barnes L, D'Amico F, Myers EN, Johnson JT. Perineural invasion in squamous cell carcinoma of the head and neck. Arch Otolaryngol Head Neck Surg 1998;124:637-40.

46. Fakih AR, Rao RS, Borges AM, Patel AR. Elective versus therapeutic neck dissection in early carcinoma of the oral tongue. Am J Surg 1989;158:309-13.

47. Fandi A, Altun M, Azli N, Armand JP, Cvitkovic E. Nasopharyngeal cancer: epidemiology, staging, and treatment. Semin Oncol 1994;21:382-97.

48. Ferlito A, Rinaldo A, Silver CE, Gourin CG, Shah JP, Clayman GL, Kowalski LP, Shaha AR, Robbins KT, Suárez C, Leemans CR, Ambrosch P, Medina JE,Weber RS, Genden EM, Pellitteri PK, Werner JA, Myers EN. Elective and therapeutic selective neck dissection. Oral Oncol 2006;42:14-25.

49. Ferlito A, Rinaldo A, Silver CE, Shah JP, Suarez C, Medina JE, Kowalski LP, Johnson JT, Strome M, Rodrigo JP, Werner JA, Takes RP, Towpik 
E, Robbins KT, Leemans CR, Herranz J, Gavilán J, Shaha AR, Wei WI. Neck dissection: then and now. Auris Nasus Larynx 2006;33:365-74.

50. Ferlito A, Robbins KT, Shaha AR, Pellitteri PK, Kowalski LP, Gavila'n J, Silver CE, Rinaldo A, Medina JE, Pitman KT, Byers RM. Current considerations in neck dissection. Acta Otolaryngol 2002;122:323-9.

51. Field JK, Spandidos DA, Malliri A, Gosney JR, Yiagnisis M, Stell PM. Elevated p53 expression correlates with a history of heavy smoking in squamous cell carcinoma of the head and neck. $\mathrm{Br} \mathrm{J}$ Cancer 1991;64:573-7.

52. Fielding LP, Fenoglio-Preiser CM, Freedman LS. The future of prognostic factors in outcome prediction for patients with cancer. Cancer 1992;70:2367-77.

53. Fisch UP. Cervical lymph flow in man following radiation and surgery. Trans Am Acad Opthalmol Otol 1965;69:846-68.

54. Fisch UP. The barrier functions of the lymph nodes in the neck of the human. Prog Clin Cancer 1970;4:97-108.

55. Friedman M, Mafee MF, Pacella BL, Strorigl TL, Dew LL Toriumi DM. Rationale for elective neck dissection in 1990. Laryngoscope 1990;100:54-9.

56. Friedman M, Roberts N, Kirshenbaum G, Colombo J. Nodal size of metastatic squamous cell carcinoma of the neck. Laryngoscope 1993;103:854-6.

57. Fu KK. Combined-modality therapy for head and neck cancer. Oncology 1997;11:1781-96.

58. Fukano H, Matsuura H, Hasegawa, Nakamura S. Depth of invasion as a predictive factor for cervical lymph node metastasis in tongue carcinoma. Head Neck 1997;19:205-10.

59. Gaffey MJ, Weiss LM. Viral oncogenesis: Epstein-Barr virus. Am J Otolaryngol 1990;11:375-81. 
60. Genden EM, Ferlito A, Shaha AR, Talmi YP, Robbins KT, Rhys-Evans $\mathrm{PH}$, Rinaldo A. Complication of neck dissection. Acta Otolaryngol 2003;123:795-801.

61. Haberal I, Celik H, Gocmen H, Akmansu H, Yoruk M, Ozeri C. Which is important in the evaluation of metastatic lymph nodes in head and neck cancer: palpation, ultrasonography, or computed tomography? Otolaryngol Head Neck Surg 2004;130:197-201.

62. Haddadin KJ, Soutar DS, Oliver RJ, Webster MH, Robertson DG, MacDonard DG. Improved survival for patients with clinically T1/T2, N0 tongue tumors undergoing a prophylactic neck dissection. Head Neck 1999;21:517-25.

63. Harai PM. Why has induction chemotherapy for advanced head and neck cancer become a United States community standard of practice? J Clin Oncol 1997;15:2050-5.

64. Hawley-Nelson P, Vousden KH, Hubbert NL, Lowy DR, Schiller JT. HPV 16 E6 and E7 proteins cooperate to immortalize human foreskin keratinocytes. EMBO J 1989;8:3905-10.

65. Henick DH, Silver CE, Heller KS, Shaha AR, El GH, Wolk DP. Sentinel node detection in N0 cancer of the pharynx and larynx. $\mathrm{Br} J$ Cancer 2002;87:711-5.

66. Henick DH, Silver CE, Heller KS, Shaha AR, El GH, Wolk DP. Supraomohyoid neck dissection as a staging procedure for squamous cell carcinomas of the oral cavity and oropharynx. Head Neck 1995;17:119-23.

67. Hill C, Benhamou E, Doyon F. Trends in cancer mortality, France 19501985. Br J Cancer 1991;63:587-90.

68. Hillsamer PJ, Schuller DE, McGhee RB Jr, Chakeres D, Young DC. Improving diagnostic accuracy of cervical metastases with computed tomography and magnetic resonance imaging. Arch Otolaryngol Head Neck Surg 1990;116:1297-301. 
69. Hoppe H, Barnwell SL, Nesbit GM, Petersen BD. Stent-grafts in the treatment of emergent or urgent carotid artery disease: review of 25 cases. J Vasc Interv Radiol 2008;19:31-41.

70. Howley PM. Role of the human papillomavirus in human cancer. Cancer Res Suppl 1991;51:5019-22.

71. Hughes CJ, Gallo O, Spiro RH, Shah JP. Management of occult neck metastasis in oral cavity squamous carcinoma. Am $\mathrm{J}$ Surg 1993;166:380-3.

72. Ikić D, Padovan I, Brodarec I, Knezević M, Soos E. Application of human leukocyte interferon in patients with tumors of the head and neck. Lancet 1981;1:1025-7.

73. Jemal A, Siegel R, Xu J, Ward E. Cancer statistics, 2010. CA Cancer J Clin 2010;60:277-300.

74. Johnson N, Franceschi S, Ferlay J, Ramadas K, Schmid S, MacDonald DG, Bouquot JE, Slootweg PJ. Squamous cell carcinoma. In: Barnes L, Eveson JW, Reichart P, Sidransky D. Editors. World Health Organization Classification of Tumours: Pathology and Genetics Head and Neck Tumours. International Agency for Research on Cancer (IARC) Press: Lyon, France. 2005:168-76.

75. Kashima HK, Kessis T, Hruban RH, Wu TC, Zinreich SJ, Shah KV. Human papillomavirus in sinonasal papillomas and squamous cell carcinoma. Laryngoscope 1992;102:973-6.

76. Keski-Säntti H, Atula T, Törnwall J, Koivunen P, Mäkitie A. Elective neck treatment versus observation in patients with T1/T2 N0 squamous cell carcinoma of oral cavity. Oral oncol 2006;42:96-101.

77. Khafif A, Lopez-Garza JR, Medina JE. Is dissection of level IV necessary in patients with T1-T3 N0 tongue cancer? Laryngoscope 2001;111:108890.

78. Kirkwood JM, Ernstoff MS. Interferons in the treatment of human cancer. $\mathrm{J}$ Clin Oncol 1984;2:336-52. 
79. Kligerman J, Lima RA, Soares JR, Prado L, Dias FL, Freitas EQ, Olivatto LO. Supraomohyoid Neck Dissection in the Treatment of T1/T2 Squamous Cell Carcinoma of Oral Cavity. Am J Surg 1994;168:391-4.

80. Kocher. Ueber Radicalheilung des krebses. Dtsch Z Chir 1880;13:13466.

81. Kowalski LP. Results of salvage treatment of the neck in patients with oral cancer. Arch Otolaryngol Head Neck Surg 2002;128:58-62.

82. Kowalski LP, Magrin J, Waksman G, Santo GF, Lopes ME, de Paula RP, Pereira RN, Torloni H. Supraomohyoid neck dissection in the treatment of head and neck tumors: survival results in 212 cases. Arch Otolaryngol Head Neck Surg 1993;119:958-63.

83. Krestan C, Herneth AM, Formanek M, Czerny C. Modern imaging lymph node staging of the head and neck. Eur J Radiol 2006;58:360-6.

84. Kurokawa H, Yamashita Y, Takeda S, Zhang M, Fukuyama H, Takahashi T. Risk factors for late cervical lymph node metastases in patients with stage I or II carcinoma of the tongue. Head Neck 2002;24:731-6.

85. La Vecchia C, Boyle P, Franceschi S, Levi F, Maisonneuve P, Negri E, Lucchini F, Smans M. Smoking and cancer with emphasis on Europe. Eur J Cancer 1991;27:94-104.

86. Lee LA, Cheng AJ, Fang TJ, Huang CG, Liao CT, Chang JT, Li HY. High incidence of malignant transformation of laryngeal papilloma in Taiwan. Laryngoscope 2008;118:50-5.

87. Leemans CR, Tiwari R, Nauta JJ, van der Waal I, Snow GB. Regional lymph node involvement and its significance in the development of distant metastases in head and neck carcinoma. Cancer 1993;71:452-6.

88. Levine PA, Seidman D. Neoplasms of the oral cavity. In: Bailey BJ, Johnson JT. Editors. Head and Neck Surgery - Otolaryngology. J.B Lippincott Company: Philadelphia. 1993;1160-75.

89. Levy R, Miller RA. Tumor therapy with monoclonal antibodies. Fed Proc 1983;42:2650-6. 
90. Li XM, Wei WI, Guo XF, Yuen PW, Lam LK. Cervical lymph node metastatic patterns of squamous carcinomas in the upper aerodigestive tract. J Laryngol Otol 1996;110:937-41.

91. Liewellyn CD, Linklater K, Bell J, Johnson NW, Warnakulasuriya KA. Squamous cell carcinoma of the oral cavity in Patients aged 45years and under: a descriptive analysis of 116 cases diagnosed in the South East of England from 1990 to 1997. Oral Oncol 2003;39:106-14.

92. Lindberg R. Distribution of cervical lymph node metastasis from from squamous cell carcinoma of the upper respiratory and digestive tracts. Cancer 1972;29:1446-9.

93. Maestro R, Dolcetti R, Gasparotto D, Doglioni C, Pelucchi S, Barzan L, Grandi E, Boiochi M. High frequency of p53 gene alterations associated with protein overexpression in human squamous cell carcinoma of the larynx. Oncogene 1992;7:1159-66.

94. Marchioni DL, Fisberg RM, do Rosario M, Latorre DO, Wunsch V. Diet and cancer of the oral cavity and pharynx: a case-control study in Sao Paulo, Brazil. IARC Sci Publ 2002;156:559-61.

95. Martin H, Del Valle B, Ehrlich H, Cahan WG. Neck dissection. Cancer 1951;4:441-99.

96. Martin $\mathrm{H}$, Morfit $\mathrm{H}$. Cervical lymph node metastasis as the first symptom of cancer. Surg Gynecol Obstet 1944;78:133.

97. Martinez-Gimeno C, Rodriguez EM, Vila CN, Varela CL. Squamous cell carcinoma of the oral cavity: a clinicopathologic scoring system for evaluating risk of cervical lymph node metastasis. Laryngoscope 1995;105:728-33.

98. McLean JN, Carlson GW, Losken A. The pectoralis major myocutaneous flap revisited: a reliable technique for head and neck reconstruction. Ann Plast Surg 2010;64:570-3.

99. Medina JE, Byers RM. Supraomohyoid neck dissection: rationale, indications, and surgical technique. Head Neck 1989;11:111-22. 
100. Meredith SC, Levine PA, Bjiurns JA, Gaffey MJ, Boyd JC, Weiss LM, Erickson NL, Williams ME. Chromosome 11q13 amplification in head and neck squamous cell carcinoma. Arch Otolaryngol Head Neck Surg 1995;121:790-4.

101. Moher D, Liberati A, Tetzlaff J, Altman DG, and the PRISMA Group. Preferred reporting items for systematic reviews and meta-analyses: the PRISMA statement. Ann Intern Med 2009;151:264-9.

102. Moreau P, Goffart Y, Collignon J. Computed tomography of metastatic cervical lymph nodes. Arch Otolaryngol Head Neck Surg 1990;116:1190-3.

103. Munger K, Phelps WC, Bubb V, Howley PM, Schlegel R. The E6 and E7 genes of the human papillomavirus type 16 together are necessary and sufficient for transformation of primary human keratinocytes. J Virol 1989;63:4417-21.

104. Nahum AM, Mullally W, Marmor L. A syndrome resulting from radical neck dissection. Arch Otolaryngol 1961;74:82-86.

105. Okamoto $M$, Nishimine $M$, Kishi M, Kirita T, Sugimura M, Nakamura M, Konishi N. Prediction of delayed neck metastasis in patients with stage I/II squamous cell carcinoma of the tongue. J Oral Pathol Med 2002;31:227-33.

106. Oldham RK. Biologicals and biological response modifiers: fourth modality of cancer treatment. Cancer Treat Rep 1984;68:221-32.

107. Ord RA, Blanchaert RH. Current management of oral cancer: A multidisciplinary approach. J Am Dent Assoc 2001;132:19-23.

108. Ossoff R, Bytell D, Hast M, Sisson G. Lymphatics of the floor of mouth and periosteum: anatomic studies with possible clinical correlations. Otolaryngol Head Neck Surg 1980;88:652-7.

109. Ozeki S, Tashiro H, Okamoto M, Matsushima T. Metastasis to the lingual lymph node in carcinoma of the tongue. J Max Fac Surg 1985;13:277-81. 
110. Panje WR. Regression of head and neck carcinoma with a prostaglandin-synthesis inhibitor. Arch Otol 1981;107:658-63.

111. Papadimitrakopoulou V. Chemoprevention of head and neck cancer: an update. Curr Opin Oncol 2002;14:318-22.

112. Patel S, Shah JP. Part II: Head and neck sites. In: Edge SB, Byrd DR, Carducci MA, Compton CA. Editors. AJCC Cancer Staging Manual. 7th eds. Springer: New York. 2009.

113. Patel SG, Shah JP. TNM Staging of Cancers of the Head and Neck: Striving for Uniformity among Diversity. CA Cancer J Clin 2005;55:24258.

114. Pierceall WE, Mukhopadhyay T, Goldberg LH, Ananthaswamy HN. Mutations in the p53 tumour suppressergene in human cutaneous squamous cell carcinomas. Mol Carcinogenesis 1991;4:445-9.

115. Pignon JP, Bourhis J, Domenge C, Designé L. Chemotherapy added to locoregional treatment for head and neck squamous-cell carcinoma: three meta-analyses of updated individual data. MACH-NC Collaborative Group. Meta-Analysis of Chemotherapy on Head and Neck Cancer. Lancet 2000;355:949-55.

116. Pillsburg HC, Clark M. A rationale for therapy of the NO neck. Laryngoscope 1997;107:1294-315.

117. Pitman KT, Johnson JT, Myers EN. Effectiveness of the selective neck dissection for the management of the clinically negative neck. Arch Otolaryngol Head Neck Surg 1997;123:917-22.

118. Po Wing Yuen A, Lam KY, Lam LK, Ho CM, Wong A, Chow TL, Yuen WF, Wei WI. Prognostic factors of clinically stage I and II oral tongue carcinoma - a comparative study of stage, thickness, shape, growth pattern, invasive front malignancy grading, martinez-gimeno score, and pathologic features. Head Neck 2002;24:513-20.

119. Pressman JJ, Simon MB. Experimental evidence of direct communications between lymph nodes and vein. Surg Gynecol Obstet 1961;113:537-41. 
120. Purtilo DT, Manolov G, Manolova Y, Harada S, Lipscomb H. Squamouscell carcinoma, Kaposi's sarcoma and Burkitt's lymphoma are consequences of impaired immune surveillance of ubiquitous viruses in acquired immune deficiency syndrome, allograft recipients and tropical African patients. In: Williams AO, O'Conor G, De-The GB, Johnson CA. Editors. Virus-associated cancers in Africa. IARC Science Publishers: Lyon, France. 1984:749-70.

121. Quak JJ, Balm AJM, Brakkee JGP, Scheper RJ, Haisma HJ, Braakhuis BJM, Meijer CJLM, Snow GB. Localization and imaging of radiolabelled monoclonal antibody against squamous-cell carcinoma of the head and neck in tumor-bearing nude mice. Int J Cancer 1989;44:534-8.

122. Rassekh $\mathrm{CH}$, Johnson JT, Myers EN. Accuracy of intraoperative staging of the NO neck in squamous cell carcinoma. Laryngoscope 1995;105:1334-6.

123. Robbins KT. Indications for selective neck dissection: when, how, and why. Oncology 2000;14:1455-64.

124. Robbins KT, Clayman G, Levine PA, Medina J, Sessions R, Shaha A, Som P, Wolf GT, American Head and Neck Society, American Academy of Otolaryngology-Head and Neck Surgery. Neck dissection classification update: revisions proposed by the American Head and Neck Society and the American Academy of Otolaryngology-Head and Neck Surgery. Arch Otolaryngol Head Neck Surg 2002;128:751-8.

125. Robbins KT, Kumar P, Regine WF, Wong FS, Weir AB 3rd, Flick P, Kun LE, Palmer R, Murry T, Fontanesi J, Ferguson R, Thomas R, Hartsell W, Paig CU,Salazar G, Norfleet L, Hanchett CB, Harrington V, Niell HB. Efficacy of targeted supradose cisplatin and concomitant radiation therapy for advanced head and neck cancer: the Memphis experience. Int J Radiat Oncol Biol Phys 1997;38:263-71.

126. Robbins KT, Shaha AR, Medina JE, Califano JA, Wolf GT, Ferlito A, Som PM, Day TA; Committee for Neck Dissection Classification, American Head and Neck Society. Consensus Statement on the 
Classification and Terminology of Neck Dissection. Arch Otolaryngol Head Neck Surg 2008;134:536-8.

127. Rouviere H. Anatomy of the Human Lymphatic System. Ann Arbor, Ml: Edwards Brother, Inc. 1938.

128. Ryan RF, Krementz ET, Truesdale GL. Salvage of stage IV intraoral squamous cell carcinomas with preoperative 5-fluorouracil. Cancer 1986;57:699-705.

129. Sakai E, Tsuchida N. Most human squamous cell carcinomas in the oral cavity contain mutated p53 tumour-suppressergenes. Oncogene 1992;7:927-33.

130. Schuller DE, Bier-Laning CM, Sharma PK, Siegle RJ, Pellegrini AE, Karanfilov B, Bellisari G, Miller R, Young DC. Tissue-conserving surgery for prognosis, treatment, and function preservation. Laryngoscope 1998;108:1599-604.

131. Sesterhenn AM, Zimmermann AP, Wagner U, Werner JA, Kalder M. Improved technique of harvesting the pectoralis major myocutaneous flap for reconstruction in female head \& neck cancer patients. Clin Otolaryngol 2008;33:378-80.

132. Shah J. Head and neck surgery. 2nd eds. Mosby-Wolfe: New York. 1996.

133. Shah JP. Patterns of cervical lymph node metastasis from squamous carcinomas of the upper aerodigestive tract. Am J Surg 1990;160:405-9.

134. Shaha AR, Spiro RH, Shah JP, Strong EW. Squamous carcinoma of the floor of the mouth. Am J Surg 1984;148:455-9.

135. Shear M, Hawkins DM, Farr HW. The prediction of lymph node metastases from oral squamous carcinoma. Cancer 1976;37:1901-7.

136. Shingaki S, Kobayashi T, Suzuki I, Kohno M, Nakajima T. Surgical treatment of Stage 1 and 11 oral squamous cell carcinoma: analysis of causes of failure. Br J Oral Maxillofac Surg 1995;33:304-8. 
137. Short SO, Kaplan JN, Laramore GE, Cummings CW. Shoulder Pain and Function After Neck Dissection with or without Preservation of the Spinal Accessory Nerve. Am J Surg 1984;148:478-82.

138. Silverberg E. Lubera JA. Cancer statistics, 1986. CA Cancer J Clin 1986:36:9-25.

139. Smoke A, Delegge MH. Chyle leaks. Consensus on management? Nutr Clin Pract 2008:23:529-32.

140. Snow GB, Patel P, Leemans CR, Tiwari R. Management of cervical lymph nodes in patients with head and neck cancer. Eur Arch Otorhinolaryngol 1992;249:187-94.

141. Sobin LH, Gospodarowicz MK, Wittekind C. UICC TNM classification of malignant tumours. 7th eds. Wiley-Blackwell: Oxford. 2009.

142. Som PM, Curtin HD, Mancuso AA. An imaging-based classification for the cervical nodes designed as an adjunct to recent clinically based nodal classifications, Arch Otolaryngol Head Neck Surg 1999;125:38896.

143. Song XM, Ye JH, Yuan Y, Zhang SY, Jiang HB, Wu YN. Radial forearm free flap for reconstruction of a large defect after radical ablation of carcinoma of the tongue and floor of the mouth: some new modifications. ORL J Otorhinolaryngol Relat Spec 2010;72:106-12.

144. Spitz MR. Epidemiology and risk factors for head and neck cancer. Semin Oncol 1994;21:281-8.

145. Stevens MH, Harnsberger HR, Mancuso AA, Davis RK, Johnson LP, Parkin JL. Computed tomography of cervical lymph nodes: staging and management of head and neck cancer. Arch Otolaryngol 1985;11:735-9.

146. Strauli P. The lymphatic system and cancer localization. In: Wiser RW, Ado TL, Wood S. Editors. Endogenous Factors Influencing Host-Tumor Balance. University of Chicago Press: Chicago. 1967:249-54.

147. Suen JY, Stern SJ. Cancer of the Neck. In: Myers EN, Suen JY. Editors. Cancer of the head and neck. $3^{\text {rd }}$ eds. WB Saunders Company: Philadelphia Pennsylvania. 1996:462-84. 
148. Suntharalingam M, Haas ML, Van Echo DA, Haddad R, Jacobs MC, Levy S, Gray WC, Ord RA, Conley BA. Predictors of response and survival after concurrent chemotherapy and radiation for locally advanced squamous cell carcinomas of the head and neck. Cancer 2001;91:548-54.

149. Syrjänen K, Syrjänen $S$, Lamberg $M$, Pyrhönen $S$, Nuutinen J. Morphological and immunohistochemical evidence suggesting human papillomavirus (HPV) involvement in oral squamous cell carcinogenesis. Int J Oral Surg 1983;12:418-424.

150. Takes RP, Baatenburg de Jong, RJ, Schuuring E, Hermans J, Vis AA, Litvinov SV, Han J, van Krieken JM. Markers for assessment of nodal metastasis in laryngeal carcinoma. Arch Otolaryngol Head Neck Surg 1997;123:412-9.

151. Tart R, Mukherji S, Avino A, Stringer S, Mancuso A. Facial lymph nodes: normal and abnormal CT appearance. Radiology 1993;188:695-700.

152. Teichgraeber JF, Clairmont AA. The incidence of occult metastases for cancer of the oral tongue and floor of the mouth: Treatment rationale. Head Neck Surg 1984;7:15-21.

153. Tryggvason K, Hoyhtya M, Salo T. Proteolytic degradation of extracellular matrix in tumor invasion. Biochem Biophys Acta 1987;907:191-217.

154. van den Brekel MWM, Bartelink H, Snow GB. The value of staging of neck nodes in patients treated with radiotherapy. Radiother Oncol 1994;32:193-6.

155. van den Brekel MWM, Castelijns JA, Stel HV, Golding RP, Meyer CJI, Snow GB. Modern imaging techniques and ultrasound- guided aspiration cytology for the assessment of neck node metastases: a prospective comparative study. Eur Arch Otorhinolaryngol 1993;250:11-7.

156. van den Brekel MWM, Stel Hv, Castelijns JA, Nauta JJP, van der Waal I, Valk J, Meijer CJLM, Snow GB. Cervical lymph node metastasis: assessment of radiologic criteria. Radiology 1990;177:379-84. 
157. Vandenbrouck C, Sancho-Garnier H, Chassagne D, Saravane D, Cachin $\mathrm{Y}$, Micheau $\mathrm{C}$. Elective versus therapeutic radical neck dissection in epidermoid carcinoma of the oral cavity: results of a randomized clinical trial. Cancer 1980;46:386-90.

158. Vidic B, Suarez-Quian C. Anatomy of the head and neck. In: Harrison LB, Sessions RB, Ki Hong W. Editors. Head and neck cancer: A multidisciplinary approach. $1^{\text {st }}$ ed. Lippincott-Raven: Philadelphia. 1998:79-114.

159. Vokes EE, Weichselbaum RR, Lippman SM, Hong WK. Head and neck cancer. N Engl J Med 1993;328:184-94.

160. Volkman. Das tiefe branchiogene Halskarzinom. Zentralbl Chir 1882;9:49-51.

161. Wang CC. Radiotherapeutic management and results of T1NO, T2NO carcinomas of the oral tongue: evaluation of boost technique. Int $\mathrm{J}$ Radiat Oncol Biol Phys 1989;17:287-91.

162. Werner JA, Davis RK. Lymphogenic metastatic spread. In: Werner JA, Davis RK. Editors. Metastases in head and neck cancers. Springerverlag: Germany. 2004:45-56.

163. Werner JA, Dunne AA, Myers JN. Functional anatomy of the lymphatic drainage system of the upper aerodigestive tract and its role in metastasis of squamous cell carcinoma. Head Neck 2003;25:322-32.

164. Werness BA, Levine AJ, Howley PM. Association of human papillomavirus types 16 and 18 E6 proteins with p53. Science 1990;248:76-9.

165. Williams ME, Gaffey MJ, Weiss LM, Wilezynski SP, Schuuring E, Levine PA. Chromosome llq13 amplification in head and neck squamous cell carcinoma. Arch Otolaryngol Head Neck Surg 1993;119:1238-43.

166. Woolgar JA. T2 carcinoma of the tongue: the histopathologist's perspective. Br J Oral Maxillofac Surg 1999;37:187-93.

167. Yamazaki Y, Saitoh M, Notani K, Tei K, Totsuka Y, Takinami S, Kanegae K, Inubushi M, Tamaki N, Kitagawa Y. Assessment of 
cervical lymph node metastases using FDG-PET in patients with head and neck cancer. Ann Nucl Med 2008;22:177-84.

168. Yonn DY, Hwang HS, Chang SK, Rho YS, Ahn HY, Kim JH, Lee IJ. CT, MR, US, 18F-FDG PET/CT, and their combined use for the assessment of cervical lymph node metastases in squamous cell carcinoma of the head and neck. Eur Radiol 2009;19:634-42.

169. Yuen AP, Ho CM, Chow TL, Tang LC, Cheung WY, Ng RW, Wei WI, Kong CK, Book KS, Yuen WC, Lam AK, Yuen NW, Trendell-Smith NJ, Chan YW, Wong BY, Li GK, Ho AC, Ho WK, Wong SY, Yao TJ. Prospective randomized study of selective neck dissection versus observation for NO neck of early tongue carcinoma. Head Neck 2009;31:765-72.

170. Yuen AP, Wei WI, Wong YM, Tang KC. Elective neck dissection versus observation in the treatment of early oral tongue carcinoma. Head Neck 1997;19:583-8.

171. Zeidman I. Experimental studies on the spread of cancer in the lymphatic system IV. Retrograde spread. Cancer Res 1959;19:1114-7. 
Name:

Date of Birth:

Place of birth:

Nationality:

Marital status:

\section{Education:}

$1977-1983$

$1983-1988$

1989

\section{Studies:}

$1990-1998$

1998

1998- 1999

20. March 2000

2005 - 2007

$2010-2011$

\section{Professional activities}

$$
\begin{aligned}
& 2000-2001 \\
& 2001-2002
\end{aligned}
$$

FASUNLA Ayotunde James

11. July, 1972

Benin - City

Nigerian

Married

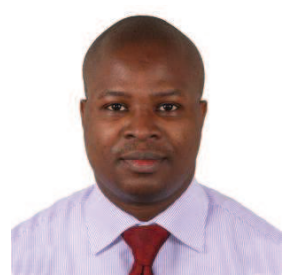

St Thomas Primary School, Akure, Nigeria

Oyemekun Grammar School, Akure, Nigeria

Graduation

Studied Medicine at Obafemi Awolowo University, Ile-lfe, Nigeria Medical examination Housemanship/Practical year at State Specialist Hospital, Akure, Nigeria Full license to practice Medicine Studied Master of Science in Surgery at the University of Ibadan, Ibadan, Nigeria.

Department of Otolaryngology, Head and Neck Surgery, UKGM, Marburg

National service

Medical officer at the department of internal Medicine, Ladoke Akintola 
University of Technology Teaching

Hospital, Osogbo, Nigeria

$2002-2009$

Resident doctor at the Department of Otorhinolaryngology,

University

College Hospital, Ibadan, Nigeria.

2009

Appointed as a lecturer at the department of Otorhinolaryngology, College of Medicine, University of Ibadan, Nigeria 


\section{List of my academic teachers}

My academic teachers were men and women in Nigeria and Germany (in alphabetical order):

\section{In Nigeria:}

Adebamowo, Adebo, Adegboye, Adejuyigbe, Ademola, Adeolu, Adeoye, Adeosun, Afolabi, Afuwape, Agbakwuru, Ajaiyeoba, Akenroye, Akinola, Akinkugbe, Akintade, Akintonmide, Akintunde, Akute, Alade, Alonge, Arotiba, Ashaye, Baiyeroju, Bekibele, Erhabor, Ezeanuole, Fadero, Fakuade, Fashola, Gila, Ige, Ijaduola, Irabor, Ladipo, Lasisi, Lawal, Malolmo, Nwaorgu, Ogundiran, Ogunlade, Ogunleye, Ogunniyi, Ogisi, Okeke, Okojie, Olawoye, Oluleye, Oluwatosin, Omigbodun, Omololu, Omotade, Onakoya, Oyedeji, Shittu, Shokunbi, Shotunmbi

In Marburg, Germany:

Sesterhenn, Teymoortash, Werner 


\section{Acknowledgement}

I would like to express my gratitude to Professor Dr. J.A. Werner for the opportunity to make my Medical doctor thesis in his hospital and also for the free access to books and journals in his library.

I sincerely thank my supervisor, Professor Dr. A.M. Sesterhenn, for all his efforts on the successful completion of the doctor thesis which included supply of the topic, motivations through supply of books and journals, purposeful criticism and reading through the thesis

I am also grateful to $\mathrm{Dr} \mathrm{N}$. Timmesfeld and Mr B.H. Green of the Institute of Medical Biometrics and Epidermiology of the Phillips University, Marburg for their detailed advice on the statistics

I thank my darling wife, Olajumoke and my children, Ayomide, Ibukunoluwa, Ayomiposi for allowing me to travel and stay in Marburg, Germany for the entire period of my study.

In particular, I would also like to appreciate my parents, my brothers and my sister for their support during my studies.

I am also grateful to all my colleagues in HNO Hospital, Marburg 


\section{Sworn declaration}

I solemnly declare that I have submitted this Medical doctor thesis titled "A Meta-analysis of the randomized controlled trials on elective neck dissection versus therapeutic neck dissection in oral cavity cancers with clinically nodenegative neck" only to the Faculty of Medicine, Philipps University in Marburg for the doctoral examination.

This doctoral work was performed by me at the department of Otolaryngology, Head and Neck Surgery, University Hospital, Giessen and Marburg GmbH, Standort Marburg under the supervision of Prof. Dr. AM Sesterhenn and Prof. Dr. JA Werner as the director of the department. I received no other assistance or help in carrying out the study other than the ones mentioned in the thesis.

I have neither applied to be admitted for doctoral studies outside Faculty of Medicine, Philipps University, Marburg nor have I submitted any other work as a dissertation to any other institution within or outside Germany.

Marburg, den 03.02.11

Ayotunde James Fasunla 